\title{
Les stratégies de subsistance des réfugiés juifs en Belgique occupée (1940-1944)
}

Insa Meinen

\section{(2) OpenEdition}

1 Journals

Édition électronique

URL : http://journals.openedition.org/cmc/333

DOI : $10.4000 / \mathrm{cmc} .333$

ISSN : 2684-3080

Éditeur

Fondation de la Mémoire Contemporaine

Édition imprimée

Date de publication : 1 décembre 2016

Pagination : 119-190

ISSN : 1377-1256

Référence électronique

Insa Meinen, «Les stratégies de subsistance des réfugiés juifs en Belgique occupée (1940-1944) 》, Les Cahiers de la Mémoire Contemporaine [En ligne], 12 | 2016, mis en ligne le 05 novembre 2019, consulté le 08 septembre 2020. URL : http://journals.openedition.org/cmc/333 ; DOI : https://doi.org/ $10.4000 / \mathrm{cmc} .333$ 


\section{Les stratégies de subsistance des réfugiés juifs en Belgique occupée (1940-1944)}

\section{Insa Meinen}

Pourquoi une étude sur les réfugiés juifs en Belgique qui se focalise sur la période de l'Occupation entre 1940 et 19441' Pourquoi une étude sur les années de l'Occupation et de la Shoah qui porte principalement sur l'activité professionnelle et les sources de revenus des Juifs ? Entre l'annexion de l'Autriche au Reich allemand en mars 1938 et l'expansion allemande en Europe occidentale en mai 1940, quelque 25.000 réfugiés juifs en provenance d'Allemagne nazie trouvèrent refuge en Belgique - un chiffre important, même en comparaison avec d'autres pays d'Europe occidentale ${ }^{2}$. À propos de ces réfugiés, on étudie en général leur parcours dans les années trente ${ }^{3}$. Dans la littérature

1 Traduit de l'allemand par Jacques Déom et, en partie, par Catherine Massange; traduction revue par Sophie Milquet et Barbara Dickschen. L'auteur est redevable au Fonds national de la Recherche scientifique (FNRS/FRS) d'avoir pu mener une année de recherche (2012-13) au Centre interdisciplinaire d'Étude des Religions et de la Laïcité de l'Université libre de Bruxelles (ULB-CIERL). Sans l'aimable appui du FNRS et du CIERL, cet essai n'aurait pas vu le jour. L'auteur souhaite également exprimer ses remerciements envers la Deutsche Forschungsgemeinschaft (DFG) d'avoir pu diriger les projets de l'Université Carl von Ossietzky : «Zwangsmigration und Holocaust » (Migration forcée et Holocauste) (2009-2012) et «Zwischen "Arisierung" und Deportation » (Entre "aryanisation" et déportations) (depuis 2014). Une partie substantielle de ces travaux a été menée dans le cadre de ces deux projets.

2 Ces réfugiés n'étaient pas tous de nationalité allemande: beaucoup d'entre eux étaient originaires de Pologne et d'autres pays d'Europe centrale et orientale.

${ }^{3}$ L'étude pionnière sur ce sujet est celle de Frank Caestecker, Ongewenste gasten. Joodse vluchtelingen en migranten in de dertiger jaren, Bruxelles, 1993 ; cette publication a été suivie de nombreuses autres du même auteur sur ce thème. Une importante contribution est celle de Jean-Philippe Schreiber, «L'accueil des réfugiés juifs du Reich en Belgique. Mars 1933 - septembre 1939 : le Comité d'Aide et d'Assistance aux Victimes de l'Antisémitisme en Allemagne », dans Les Cahiers de la Mémoire contemporaine, 3, 2001, pp. 23-71. L'étude d'Insa Meinen et d'Ahlrich Meyer, avec la collaboration de Jörg Paulsen, Vervolgd van land tot land. Joodse vluchtelingen in West-Europa 19381944, traduit de l'allemand par Iannis Goerlandt, Anvers, 2014, concerne l'époque de l'Occupation, mais ne comporte qu'une esquisse de la situation matérielle de ces réfugiés. 
sur la persécution des Juifs sous l'occupation allemande, ces réfugiés ont en revanche à peine été pris en compte jusqu'ici. On a aussi supposé que peu d'entre eux résidaient encore en Belgique à cette époque 4 . La réalité se présente en fait différemment. Nombre d'émigrés ont certes poursuivi leur déplacement vers d'autres pays dans les années précédentes. En mai 1940, 3.500 Juifs allemands et autrichiens au moins, tous hommes en âge de porter les armes, ont été amenés de force en France par l'administration belge 5 . Un autre groupe important se joignit à l'exode des Belges. Mais cela ne change rien au fait que de très nombreux réfugiés juifs vivaient en Belgique sous l'occupation allemande. D'après notre estimation, il s'agissait de plus de 13.000 hommes, femmes et enfants. Cela signifie que $23 \%$ des Juifs en Belgique avaient fui l'Allemagne, ce qui représente presque un quart de la population juive de Belgique de l'époque ${ }^{6}$.

On pourrait penser que le destin des réfugiés juifs en Belgique occupée ne se distinguait pas de celui de la population juive en général. En effet, la persécution antijuive mise en œuvre par le commandant militaire finit par faire de tous ceux que les dirigeants nazis définissaient comme juifs des parias. Dans ce contexte, la question de savoir s'ils disposaient des droits de résidence ordinaires ou s'ils étaient entrés dans le pays en tant que réfugiés irréguliers ne jouait aucun rôle. Mais l'invasion des troupes allemandes constitua pour les réfugiés une catastrophe singulière. N'étant arrivés la plupart du temps en Belgique qu'en 1938 ou 1939, ils avaient depuis l'accession de Hitler au pouvoir vécu l'escalade progressive de la politique raciale nationale-socialiste.

4 Les biens des victimes des persécutions anti-juives en Belgique. Spoliation Rétablissement des droits. Résultats de la Commission d'étude. Rapport final, Bruxelles, Services du Premier Ministre, 2001 (www.combuysse.fgov.be), p. 147.

5 M. Steinberg, L'Étoile et le fusil. La question juive, 1940-1942, Bruxelles, 1983, pp. 8588 ; R. Van Doorslaer - E. Debruyne - F. Seberechts - N. Wouters, La Belgique docile. Les autorités belges et la persécution des Juifs en Belgique pendant la Seconde Guerre mondiale, 2 vol., Bruxelles, 2007 (ultérieurement cité : La Belgique docile...), pp. 161263 (Debruyne). Voir aussi M. Bervoets-Tragholz, La Liste de Saint-Cyprien, Bruxelles, 2006.

6 Voir à ce sujet : I. Meinen - A. Meyer, op. cit., pp. 119-123. Parmi ces réfugiés, qui vivaient encore en Belgique sous l'Occupation, il y avait au moins 1.000 hommes, femmes et enfants qui avaient quitté l'Allemagne dès le début des années trente. 
Dès les années trente, bien avant le début de la « solution finale », la persécution des Juifs détermina et empoisonna la vie quotidienne en Allemagne dans une mesure que l'on peut difficilement se représenter. De nombreux réfugiés avaient de surcroît vécu dans leur chair les pogroms de 1938. Certains avaient été blessés; un nombre très considérable d'hommes avaient été envoyés en camps de concentration et finalement expulsés du Reich allemand avant leur épouse ${ }^{7}$. Souvent, les Juifs réfugiés se voyaient contraints de se séparer de leurs parents les plus proches. La plupart avaient pour ainsi dire tout perdu : le gîte et le couvert, leurs biens et possessions, leur situation professionnelle et leurs revenus. C'est dans des conditions hostiles et épuisantes, de manière principalement illégale, qu'ils avaient réussi à gagner la Belgique. Leur tentative de trouver une issue à leur situation désespérée échoua en mai 1940 : l'occupation de la Belgique ramena sous la férule du régime nazi ceux qui avaient déjà échappé aux exécuteurs de la folie raciale.

En outre, ils n'étaient encore nullement établis de manière formelle en Belgique en 1940. Seule une petite minorité d'entre eux avait été autorisée à s'installer et à s'intégrer professionnellement dans leur pays d'accueil. L'État belge ne refoulait généralement pas en Allemagne les autres réfugiés juifs parvenus dans le pays par des voies clandestines. Ils étaient plutôt tolérés à titre transitoire et moyennant la condition d'émigrer au plus vite vers l'Amérique, la Palestine ou toute autre destination. La crise internationale des réfugiés déclenchée en 1938 par la pressante et brutale politique d'expulsion du gouvernement allemand amena néanmoins les États prêts à l'accueil à fermer leurs frontières aux Juifs venant d'Allemagne. De nombreux réfugiés qui ne souhaitaient ou ne devaient à l'origine rester que provisoirement en Belgique ne pouvaient en conséquence plus quitter le pays. Ils conservèrent toutefois un statut temporaire. Ils subissaient de surcroît une stricte interdiction de travail et furent au besoin soutenus par des comités d'aide privés juifs. Dépouillés dès avant leur fuite face aux nationaux-socialistes et exclus depuis lors du marché du travail belge, la

\footnotetext{
7 Voir à ce sujet : I. Meinen, " "Je devais quitter le pays dans les dix jours, sinon on m'aurait mis dans un camp de concentration". Réfugiés juifs d'Allemagne nazie en Belgique (1938-1944) », dans Les Cahiers de la Mémoire Contemporaine, 10, 2011, pp. 175-212.
} 
situation matérielle de la plupart des réfugiés - même en comparaison avec le reste de la population juive principalement immigrée d'Europe orientale en Belgique après la Première Guerre mondiale - s’avéra extrêmement précaire lorsque la Wehrmacht écrasa la Belgique.

Comment se débrouillèrent-ils sous l'occupation allemande? Dans quelles conditions et dans quelles professions les réfugiés trouvèrent-ils un emploi ? Quelle est la distinction entre les sources de revenus des femmes et des hommes, qui faisaient vivre les familles ? Quelle forme prenait le travail illégal des réfugiés, notamment au marché noir, florissant sous la domination allemande ? Quels étaient les risques et contraintes liés au travail illégal ? Quel était l'effet de la persécution antijuive sur le travail des réfugiés? Que peut-on dire du revenu des réfugiés et des frais de subsistance en Belgique occupée? Comment ceux qui ne travaillaient pas assuraient-ils leur subsistance? À quels moyens les veuves et personnes âgées recouraient-elles?

Si cet article évoquera quelques mesures administratives du commandant militaire allemand et des autorités belges, son sujet n’est pas tant les relations politiques et policières avec les réfugiés, qui dominent si souvent l'historiographie touchant l'exode des Juifs d'Allemagne nazie, que la situation et les activités des réfugiés, en particulier leurs relations de travail et leurs stratégies de survie.

Les questions portant sur la lutte pour la survie économique des persécutés n’apparaissent que de manière limitée dans la littérature scientifique sur la persécution des Juifs entre 1940 et 1944. Il est étonnant de constater que ce n'est pas seulement le cas pour les réfugiés, mais pour l'ensemble de la population juive. La recherche entamée au plan international dans les années 1990 sur l"“aryanisation" s'est attachée principalement à faire la lumière d'une part sur la spoliation des Juifs et de l'autre sur le sort de leurs biens. Le travail sur ces sujets fondamentaux était indispensable et la contribution belge de la Commission Buysse mérite toujours d'être lue ${ }^{8}$. Une question demeure néanmoins mal éclaircie, à savoir celle de la manière dont les Juifs coupés de leurs sources de revenus ont assuré leur subsistance ${ }^{9}$. Cette

${ }^{8}$ Les Biens des victimes..., op. cit.

${ }_{9}$ Des précisions, en particulier sur le soutien matériel aux Juifs paupérisés, se trouvent dans la contribution de Catherine Massange, «La politique sociale », dans J.-Ph. Schreiber - R. Van Doorslaer (dir.), Les Curateurs du Ghetto. L'Association des Juifs en 
question est loin d'être secondaire, surtout pour l'époque de la Shoah. Il existait en effet vraisemblablement un lien entre revenu et survie, entre la situation matérielle des Juifs et le risque d'être déporté. C'est à l'été 1942 que commença la déportation depuis la Belgique vers Auschwitz. Très tôt, beaucoup de Juifs s'efforcèrent de se mettre à l'abri en fuyant leur logement avant d'être arrêtés ${ }^{10}$. Or il fallait des liquidités pour obtenir des faux papiers ou une cache ${ }^{11}$. Comment pouvait-on survivre dans la clandestinité ? Ceux qui ne disposaient de moyens d'aucune sorte pouvaient-ils aussi espérer être sauvés? Ou bien les pauvres étaient-ils les plus en danger? À des questions de cet ordre, l'étude ici proposée sur le travail et la subsistance des réfugiés juifs ne peut fournir qu'une réponse provisoire ${ }^{12}$.

Les résultats qu’on va lire s'appuient sur l'analyse de dossiers de provenances diverses, relatifs aux personnes. Les plus de 3.300 dossiers individuels de la Police des Étrangers passés en revue, qui concernent les réfugiés juifs d'Allemagne, contiennent des centaines d'indications

Belgique sous l'occupation nazie, Bruxelles, 2004, pp. 277-316. Pour d'autres éléments sur l'aide sociale, voir : La Belgique docile..., op. cit., pp. 540 sqq. (Seberechts).

10 Le passage massif des Juifs dans la clandestinité débuta plus tôt que ce qu'on a longtemps cru. Dès août 1942, dès le premier mois donc de la déportation, la SIPO-SD de Bruxelles informa Berlin que les Juifs se défaisaient des étoiles jaunes et quittaient leur logement. I. Meinen, La Shoah en Belgique, Bruxelles, 2012, pp. 204-205.

11 Cela était vrai pour la majorité des Juifs qui ne faisaient pas partie de la Résistance organisée, ni ne pouvaient être aidés par le Comité de Défense des Juifs ou par une autre forme d'assistance. Même si des logements clandestins étaient loués sans surcoût, il fallait au moins payer un loyer. Voir à ce sujet : A. Meyer, « Faux papiers. Un chapitre ignoré de la Résistance juive en Belgique », dans Les Cahiers de la Mémoire contemporaine, 10, 2011, pp. 213-269.

12 On n'a jusqu'à présent que trop peu étudié les liens entre les chances de survie des Juifs et les facteurs économiques. Avec leur thèse sur l'économie de la Solution finale, "Ökonomie der "Endlösung" ", avancée et débattue au niveau international dans les années quatre-vingt, Susanne Heim et Götz Aly relient la Shoah et d'autres crimes de masse commis par le régime nazi aux concepts de réorganisation démographique d'Ordre nouveau, développés par des experts allemands en économie et en sciences sociales dans les années trente et quarante, qui nièrent le droit à la vie de millions de personnes dans l'intérêt de l'économie allemande. Cf. G. Aly - S. Heim, Les Architectes de l'extermination. Auschwitz et la logique de l'anéantissement, Paris, 2006. Ce travail a fait beaucoup avancer la recherche sur le nazisme, même si l'interprétation utilitariste du judéocide qui en découle est restée controversée. La relation entre l'économie et la Solution finale que nous traitons ici se rapporte plus aux moyens d'existence des Juifs persécutés qu'aux liens avec les intérêts et plans allemands. 
quant à des activités lucratives et rémunératrices sous l'Occupation ${ }^{13}$. Plusieurs centaines d'autres documents personnels pertinents figurent dans les archives des autorités allemandes d'occupation (surtout le Devisenschutzkommando et la Brüsseler Treuhandgesellschaft), de la communauté juive obligatoire (Association des Juifs en Belgique, $\mathrm{AJB})$, ainsi que dans les papiers laissés par les réfugiés déportés du camp de Malines («reliques ») $)^{14}$. Des informations supplémentaires quant au sort des personnes concernées proviennent, sauf mention contraire, des registres de la population juive établis sous l'occupation allemande ou des listes de convois des trains de la mort MalinesAuschwitz ${ }^{15}$. L'identification et la synthèse d'une masse de cas particuliers dispersés constituent certes une méthode fastidieuse, mais elle fournit des informations que l'on aurait de la peine à obtenir autrement. De plus, la recherche portant sur des personnes offre l'avantage que l'on ne perd ainsi pas de vue les persécutés. Sera présenté dans ces

13 Pour repérer les dossiers de réfugiés juifs dans le fonds d'archives de la Police des Étrangers déposé aux Archives générales du Royaume (AGR, Bruxelles), nous avons choisi parmi les 20.000 dossiers individuels des Juifs déportés de Belgique (identifiés par Patricia Ramet) tous ceux qui pouvaient concerner les réfugiés arrivés d'Allemagne à partir de 1938. Parmi ces 6.000 dossiers, nous en avons examiné 3.800 , dont 3.300 ont été jugés pertinents. Nous avons aussi consulté les dossiers de 250 réfugiés juifs qui ont échappé à la déportation. Laurence Petrone et Yasmina Zian nous ont aidée à dépouiller ces dossiers.

14 Le Devisenschutzkommando (DSK), département du Ministère des Finances du Reich, et la Brüsseler Treuhandgesellschaft (BTG), pilotée par le département économique de l'Administration allemande, se chargèrent de manière décisive de priver les Juifs de la jouissance de leurs biens. Les dossiers de la DSK Belgique sont conservés au Centre d'Études et de Documentation Guerre et Sociétés contemporaines (Ceges, Bruxelles) ; les Archives du Séquestre de la BTG se trouvent aux AGR; les dossiers de l'AJB et les « Reliques » sont à Kazerne Dossin, à Malines. Une base de données de la population juive de Belgique et de ses biens a été constituée par la commission belge d'enquête sur les dédommagements de l" "aryanisation" (Commission Buysse) ; nous n'y avons pas eu accès, car le programme informatique utilisé n'est pas compatible avec les principaux systèmes d'exploitation actuels (information communiquée oralement par l'historien Rudi Van Doorslaer, qui a dirigé l'équipe de recherche dans la seconde phase des travaux, 2.4.2007).

15 Le Registre des Juifs de Belgique, le fichier des membres de l'AJB et les listes de transport sont disponibles sous forme de scans et sous forme numérisée à Kazerne Dossin (Malines). Nous avons consulté le fichier du chargé des affaires juives du SipoSD de Bruxelles (« fichier SD »), au Service des Victimes de la Guerre (Service public fédéral de la Sécurité sociale, SVG, Bruxelles). 
pages un choix limité de cas individuels typiques. Il s'agit quasi exclusivement de l'histoire de réfugiés victimes de la Shoah. Nous entendons comprendre comment ceux-ci ont tenté d'affirmer leur droit à l'existence avant que leur vie ne leur soit ravie dans la violence. Dans la mesure où il s’agit de personnes qui ont survécu à l'époque nazie, ou quand on peut faire état d'informations à traiter confidentiellement, les données personnelles sont généralement abrégées pour des motifs de protection de la vie privée.

\section{De l'interdiction de travail au marché secondaire du travail}

Après le début de l'occupation allemande, les Juifs qui avaient fui l'Allemagne et l'Autriche se trouvèrent pris au piège. Cependant, les indigents purent avoir recours à l'assistance publique sans difficulté. Cela signifie que les réfugiés juifs de l'avant-guerre touchèrent massivement à partir du printemps 1940 des allocations des bureaux communaux d'aide sociale ${ }^{16}$. Du reste, les caisses belges, de toute façon pillées par la puissance allemande d'occupation, servaient donc de surcroît à soutenir de nombreuses personnes que le régime nazi avait exilées après les avoir dépouillées.

Une partie des réfugiés renoncèrent après quelques mois aux subsides et trouvèrent un travail. La Police des Étrangers chercha à réduire le cercle des allocataires restants en exigeant de beaucoup d'entre eux d'assumer une occupation assurant des revenus. Ce faisant, elle prêta une attention particulière aux hommes aptes au travail qui avaient déjà attiré auparavant l'attention de la Sûreté belge, parce qu'on leur reprochait une condamnation antérieure ou une infraction aux dispositions du droit des étrangers. Un second groupe visé était constitué par les familles nombreuses, tandis que des femmes isolées se trouvaient moins souvent au centre de l'intérêt policier. Une série de

\footnotetext{
16 Cela découle des dossiers individuels de la Police des Étrangers belge. Dès la mi-mai 1940, le Ministère belge de la Justice informe la Croix-Rouge du fait que les réfugiés nécessiteux seront à l'avenir soutenus par l'administration civile. Rapport d'un ancien représentant du Comité d'Assistance aux Réfugiés juifs (CARJ), 26.09.1940, publié dans Die Verfolgung und Ermordung der europäischen Juden durch das nationalsozialistische Deutschland 1933-1945, Dokumentenedition (VEJ), tome 5, Munich, 2012, Doc. 156.
} 
réfugiés se firent enregistrer comme journaliers par l'administration belge du travail, qui procura un emploi à plus d'un. Parfois, les fonctionnaires responsables de la Police des Étrangers se contentèrent d'une attestation de recherche d'emploi ou d'une attestation médicale d'incapacité de travail. Dans d'autres cas, ils exercèrent des pressions sur les personnes concernées. Cependant, quelques réfugiés vécurent de l'assistance officielle durant des périodes prolongées. Mais beaucoup renoncèrent à recevoir cet argent, que ce soit d'initiative personnelle ou sous la pression de la police belge.

\section{Couture à domicile}

Israel Fingerhut, un négociant en confection expulsé de Berlin, d'origine polonaise, avait en vain espéré recevoir, avec l'aide d'un neveu vivant à Brooklyn, un visa pour New York et avait fait des démarches pour obtenir également une autorisation d'immigration pour la Palestine, avant que le régime nazi ne le rattrape, lui et sa famille, dans son exil en Belgique ${ }^{17}$. Ses quatre enfants avaient en 1940 entre 9 et 15 ans. L'aide publique anversoise soutenait cette famille de six personnes, qui fut à l'hiver 1940-1941 expulsée vers la province belge du Limbourg et ne put regagner Anvers qu'en juin 1941. En décembre 1941, la Police des Étrangers mit Fingerhut en demeure de trouver un travail endéans le mois pour assurer l'entretien des siens. Peu après, la famille emménagea à Bruxelles, où Fingerhut se fit « ouvrier tailleur » à domicile et ne sollicita plus l'aide sociale. Sa fille aînée apprit le métier de modiste. À la mi-1942, elle et le fils aîné reçurent des autorités d'Occupation 1" "ordre de mise au travail" - convocation camouflée pour la déportation et la mort. Ils durent se présenter à la caserne Dossin à Malines, où les Allemands avaient établi un camp de transit ${ }^{18}$. Le bureau de Bruxelles de la Sicherheitspolizei et du SD (Sipo-SD) les déporta tous deux le 4 août 1942 par le premier convoi qui menait de Malines à Auschwitz. Aucun membre de cette famille n'échappa à la

\footnotetext{
17 Archives générales du Royaume, Bruxelles (AGR), Police des Étrangers, Dossiers individuels, A 330.192.

18 En ce qui concerne l'état récent de la recherche sur le camp de Malines, voir L. Schram, La caserne Dossin à Malines 1942-1944 - Histoire d'un lieu, thèse de doctorat inédite, Université libre de Bruxelles, 2015 (directeur : Pieter Lagrou).
} 
« solution finale ». Le 8 septembre 1942, Bina Abramowicz, épouse Fingerhut, partait vers la mort avec ses deux jeunes enfants. Fingerhut lui-même se trouvait dans le XXIIIe convoi, qui quitta la Belgique en janvier 1944.
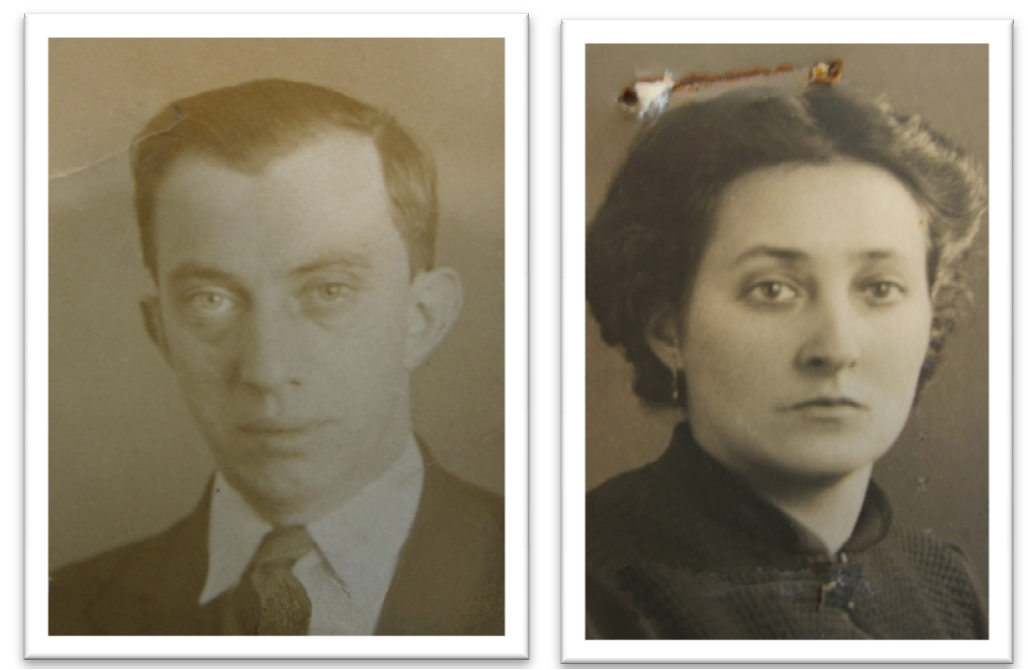

Israel Fingerhut et Bina Abramowicz-Fingerhut. (CAGR

Ceux qui avaient des compétences comme artisans-tailleurs trouvaient plutôt plus facilement du travail en Belgique occupée, par rapport à d'autres artisans, comme les tapissiers. Dans beaucoup de familles, mari et femme travaillaient comme tailleurs dans le même appartement. Josef Tillinger, un négociant en confection d'origine roumaine, fut en 1939 - avant l'invasion allemande de la Belgique - verbalisé par la police municipale à Anvers, où il avait trouvé refuge, parce qu'il faisait du porte-à-porte sans licence avec des tissus. En 1940, alors qu'il avait 49 ans, lui et sa famille (c'est-à-dire son épouse de dix ans plus jeune et leur fille de 11 ans) étaient soutenus par l'assistance publique anversoise. L'année suivante, la famille gagna Bruxelles, où les époux - Salomea Tillinger-Glasberg était corsetière diplômée - effectuèrent des travaux de réparation et de retouche à 
domicile ${ }^{19}$. Ils chiffraient leur salaire hebdomadaire à 350 francs belges en moyenne ${ }^{20}$. En janvier 1944, l'administration du camp de Malines enregistra toute la famille pour le XXII convoi.

Les situations personnelles des tailleurs, telles que leur âge ou leur situation familiale, étaient très différentes. Le jeune Karl Ehrlich, membre dans sa ville natale de Vienne des Jeunesses communistes, était célibataire et apatride. Après son expulsion par les nouvelles autorités nationales-socialistes, il arriva en Belgique au milieu de 1938. En avril 1940, il était mentionné - à l'âge de 20 ans - dans un rapport de police pour avoir pris part à des discussions sur le communisme dans un restaurant bruxellois. En 1941, exerçant sa profession de tailleur à domicile, son revenu n'atteignait que 100 francs belges par semaine, comme il en informa lui-même la police. Pour la mansarde qui lui servait d'habitation et d'atelier, il payait 85 francs par mois ${ }^{21}$. Karl Ehrlich fut déporté par le $\mathrm{X}^{\mathrm{e}}$ convoi en septembre 1942. Quant aux tenanciers du restaurant en question, il s'agissait d'un couple de réfugiés juifs de Vienne, également victimes de la Shoah ${ }^{22}$.

Dans un certain nombre de familles, c'était la fille aînée ou le fils aîné qui gagnait l'argent du ménage. Hannchen Hoffman passa son vingtième anniversaire en 1940 en Belgique. Deux ans plus tôt, elle avait dû quitter en catastrophe avec ses parents Ludwigshafen, où elle était née. Ses parents étaient venus au monde en Galicie austrohongroise. Lorsque les chars allemands firent irruption en Belgique, la mère avait déjà 56 ans. Le père, Israel Hoffman, 54 ans, était rabbin et s'était également occupé d'inventer des remèdes contre les tumeurs. Pour nourrir sa famille, Hannchen Hoffman - qui avait déjà été autrefois bonne d'enfants - accepta (au plus tard en 1942) des travaux de

19 Comme les femmes mariées en Allemagne à cette époque portaient le nom de leur mari, alors qu'elles se trouvent dans des fichiers belges sous leur nom de jeune fille, nous mentionnons les deux noms.

${ }^{20}$ AGR, Police des Étrangers, Dossiers individuels, A 348.013.

21 Ibid., A 307.543.

${ }^{22}$ La tenancière du restaurant était Regina Metzendorf-Porjez. Ayant également fui vers la Belgique en 1938, elle fut arrêtée en septembre 1942 par le DSK dans un café bruxellois et déportée par le XIVe convoi. Son mari, Salomon Porjez vivait caché à Bruxelles avant de tomber aux mains de la Sipo-SD allemande en décembre 1942. Il fut déporté en janvier 1943. Ceges, AA 585/110; AGR, Police des Étrangers, Dossiers individuels, A 300.744. 
couture qui servaient à l'équipement de la Wehrmacht ${ }^{23}$. En janvier 1944, la Gestapo envoya Hannchen Hoffman, sa mère et son père à Auschwitz.

Il est frappant de remarquer que, pour la plupart, les réfugiés n'étaient pas établis à leur compte, mais travaillaient à domicile pour des firmes tierces. Un travail à domicile qualifié en tant que couturière ou tailleur supposait de posséder une machine à coudre. Il y eut des réfugiés qui réussirent à faire sortir leur machine d'Allemagne ${ }^{24}$, mais les dispositions antijuives qui y étaient en vigueur, tout comme le fait que dans près de $90 \%$ des cas la fuite devait s'effectuer sans visa d'entrée - donc par des voies secrètes et dans la précipitation - rendaient difficile d'emporter son outil de travail ${ }^{25}$. Dans la mesure où ils n'avaient pas la chance de pouvoir louer en Belgique un logement avec machine à coudre - même si cela pouvait arriver - l'acceptation d'un travail a sans doute dépendu de la possibilité de se procurer une machine ou d'en utiliser une de location. Manifestement, certaines tailleuses pauvres qui avaient fui l'Allemagne ne purent exercer leur métier en Belgique parce qu'elles n'y disposaient pas d'une machine ${ }^{26}$.

\section{Autres occupations précaires}

Outre l'activité de tailleur, la plus répandue, quelques autres métiers sont documentés. Il y eut ainsi des réfugiés qui effectuaient à domicile, comme salariés, des travaux de cordonnerie ou exerçaient le métier de maroquinier. Certains trouvèrent à s'employer temporairement comme garçons de course, aides-cuisiniers ou travailleurs agricoles. D'autres donnaient un coup de main comme camionneurs, aidescoiffeurs ou travailleurs dans la reconstruction d'un pays ravagé par la guerre $^{27}$. La précarité de la plupart des activités est typique du travail des réfugiés sous l'occupation allemande. Ceux qui voulaient gagner

\footnotetext{
23 Kazerne Dossin, Reliques Israel Hoffman. Pour deux cas similaires, voir : I. Meinen, " "Je devais quitter le pays dans les dix jours"... » (voir note 6), pp. 202-203 ; I. Meinen - A. Meyer, « La Belgique, pays de transit. Juifs fugitifs en Europe occidentale au temps des déportations de 1942 ", dans Cahiers d'Histoire du Temps présent, 20, 2008, pp. 145-194, ici p. 171.

${ }_{24}$ Interrogatoire de Klara S., 29.8.1940, DSK-Brüssel, Ceges, AA 585/52/2.

25 Voir à ce propos I. Meinen - A. Meyer, op. cit., p. 39.

26 Kazerne Dossin, AJB, 21D, Service social, Rapports individuels, 150, 140.
} 
leur vie devaient souvent exercer diverses professions et petits travaux à tour de rôle. C'est ce que montrent les exemples d'un cordonnier qui, avec sa femme, fouillait les poubelles et nettoyait des bouteilles, ainsi que celui d'un ex-voyageur de commerce qui travaillait ponctuellement dans une poissonnerie et se livrait au marché noir pour des tiers, avant d'accomplir, avec sa femme et sa fille, des travaux de couture à domicile.

Une famille de cinq personnes originaire de Vienne, celle du fabricant de pantoufles Alexander Mayer, chercha refuge en Belgique dès fin 1938. En 1939, la fille cadette décéda à Anvers. À partir de 1941, la police belge pressa le mari de 42 ans de s'occuper de l'entretien de sa famille et de cesser de s'en remettre à l'assistance publique communale. Mayer fit valoir qu'il pouvait certes travailler comme cordonnier, mais qu'il ne disposait pas de l'outillage nécessaire, ni ne possédait l'argent nécessaire à l'acheter ${ }^{28}$. En mai 1941, il travaillait toutefois comme cordonnier, sans que la manière dont il s'était procuré les outils ressorte des documents. En septembre 1941 au plus tard, il n’exerça plus ce travail. Sous la pression de la Police des Étrangers, la famille renonça pourtant à toucher des allocations communales. Au lieu de quoi, Mayer et sa femme fouillèrent les poubelles à la recherche de choses utilisables à vendre, ce qui leur faisait de 20 à 25 francs belges par jour, comme ils le déclarèrent aux autorités. En novembre 1942, la police de Bruxelles constata qu'Alexandre Mayer, dont la femme avait au printemps mis au monde un nouvel enfant, était entretemps employé par une société où il nettoyait des bouteilles et gagnait 240 francs par semaine $^{29}$. À ce moment, son fils aîné, Hans, avait déjà été assassiné à Auschwitz. Lui-même et les autres membres de la famille se débrouillèrent tant bien que mal en Belgique, jusqu'à ce que les forces d'Occupation les déportent en avril 1944 par le XXIVe convoi.

27 AGR, Police des Étrangers, Dossiers individuels, A 329.856, A 342.161, A 307.705, A 324.226, A 326.735, A 308.246, A 329.827, A 353.286. Interrogatoire de Berthold R., 29.8.1940, DSK-Brüssel, Ceges, AA 585/52/2. Interrogatoire de Saul K., 31.7.1942, DSK-Brüssel, Ceges, AA 585/54/5.

28 AGR, Police des Étrangers, Dossiers individuels, A 330.772.

${ }^{29}$ L'office du travail (Arbeitsamt) de Bruxelles l'avait probablement envoyé là, parce que depuis la mi-1942 les ordonnances antijuives du Militärbefehlshaber n'autorisaient presque plus d'emploi régulier pour les Juifs que dans le cadre de l'Arbeitseinsatz. 
Le réfugié Peisach Körner, voyageur de commerce, sa femme et ses deux fils nés à Vienne, encore en âge scolaire, touchaient l'aide sociale de la commune de Saint-Josse, pour un montant de 147 francs belges par semaine ${ }^{30}$. Telle était leur situation en janvier 1941. Poussé par la police, le père de famille, de 44 ans, s'inscrivit au bureau belge de placement. Début avril, il travaillait comme homme de peine dans une poissonnerie, où il touchait 35 francs (plus les frais) par jour. À la mi1941, il vendait des tissus qui n'étaient pas déclarés dans les formes. L'administration belge lui infligea donc deux amendes et confisqua sa marchandise. Mais sa femme, Helen Körner-Schleier, travaillait à domicile avec l'aide de sa fille Berty et procurait de la sorte à la famille un revenu qui aurait atteint de 300 à 350 francs par semaine. L'enquête de police indiquait que Körner se livrait de surcroît, à la commission, au commerce de tissus au noir. En 1942, il travaillait légalement dans son appartement pour une firme de tailleurs de Schaerbeek, qui lui payait chaque semaine quelque 170 francs belges. Sa femme et sa fille continuaient leur travail de tailleuses, leur rémunération hebdomadaire se situant entre 350 et 400 francs. Le loyer de leur appartement atteignait 70 francs. Le 4 août 1942, la police belge constata cet état de choses dans un rapport. Le même jour, toute la famille Körner fut déportée à Auschwitz par le premier train de la mort parti de Malines. Elle avait probablement été arrêtée peu auparavant par la police allemande.

\section{Travaux féminins typiques}

Parmi les réfugiés qui cousaient à domicile, on comptait de nombreuses femmes et jeunes filles. Il pouvait s'agir d'un atelier familial où travaillaient ensemble mari et femme ou mère et fille. Il se trouvait aussi des femmes qui travaillaient seules. Dans la mesure où elles n'étaient pas isolées, elles travaillaient pour entretenir leurs parents et frères et sœurs, leur mari ou leurs enfants ${ }^{31}$. Plus d'une avait acquis

30 AGR, Police des Étrangers, Dossiers individuels, A 303.923.

31 Voir par exemple : AGR, Police des Étrangers, Dossiers individuels, A 385.706, A 299.084, A 353.143, A 319.109. Interrogatoire de Bruno F., 31.7.1942, DSK-Brüssel, Ceges, AA 585/54/5. Kazerne Dossin, AJB, 21D, Service social, Rapports individuels, 140. 
une formation de tailleuse ou de couturière. D'autres effectuaient des travaux de couture ou de reprisage pour des tiers, connaissances ou amis, sans avoir exercé professionnellement ces activités avant de fuir l'Allemagne. La rémunération constituait quelquefois l'unique revenu de la famille, ou un appoint au revenu d'un autre membre de la famille ou à une allocation sociale insuffisante. Ce type de travaux se trouve fréquemment mentionné dans les dossiers individuels. Les données issues des rapports de police correspondaient-elles pour autant à la réalité ? Comme la Police des Étrangers ouvrait une enquête quand on pouvait soupçonner qu’une activité rémunérée n’était qu’alléguée, mais non exercée, on peut considérer qu’en fait un bon nombre de femmes et de jeunes filles réfugiées d'Allemagne cousaient.

Le travail des couturières non professionnelles s'inscrivait dans un processus d'apprentissage traditionnel des jeunes filles et correspondait aux attentes à l'égard d'une «bonne mère de famille ». Sous l'occupation allemande, les émigrantes effectuaient ces travaux habituellement réalisés gratuitement pour leurs proches - pour se procurer de l'argent. Certaines femmes tricotaient ou faisaient du crochet, d'autres reprisaient des chaussettes. Venue de Breslau, Hertha RosenGoldstein se réfugia en 1939 avec sa fille auprès de son mari qui, fin 1938, avait réussi à immigrer en Belgique. Il faisait partie de ces hommes, allemands et autrichiens, expulsés en mai 1940 vers le Midi de la France par les autorités belges. Herta Rosen-Goldstein resta seule, à l'âge de 29 ans, en Belgique à présent occupée avec sa fille, qui n'avait pas encore 3 ans. Comme l'allocation de 133 francs qu'elle recevait par semaine de l'assistance sociale ne suffisait pas, elle tricotait des gants contre rémunération. Au printemps 1943, avec la recette, elle arrivait tout juste à payer le loyer de sa chambre et d'une cuisine, qui se chiffrait à 228 francs belges par mois. La pénibilité de cette activité apparaît dans un rapport de la communauté obligatoire des Juifs en Belgique (Association des Juifs en Belgique - AJB). Son service social s'enquit en effet d'Hertha Rosen-Goldstein et établit en conclusion : «Son état de santé est bon d'habitude, mais elle est affaiblie par le travail manuel. »32 Au printemps 1944, la police allemande mit la main

32 Kazerne Dossin, AJB, 21D, Service social, Rapports individuels, 193, Rapport du 6.5.1943. Voir aussi sur cette famille : AGR, Police des Étrangers, Dossiers individuels, A 329.241, ainsi que M. Bervoets-Tragholz, La Liste de Saint-Cyprien, op. cit., p. 395. 
sur la mère et la fille. Hertha Rosen-Goldstein et sa fille Ilse se trouvaient dans l'avant-dernier convoi qui quitta la Belgique pour Auschwitz.

D'ailleurs, même effectué jusqu'à épuisement, le travail manuel ne pouvait servir que d'appoint. Nous n'avons trouvé dans les documents qu'un seul cas où un réfugié - et il s'agit ici exceptionnellement d'un homme - affirmait gagner prétendument sa vie en tricotant des pullovers, des chaussettes et autres articles de bonneterie. Peut-être disposait-il d'une machine à tricoter professionnelle. En tout cas, à la fin de 1941, il parvenait à gagner par jour, selon ses propres déclarations, 30 francs belges; son loyer mensuel, 50 francs pour une chambre meublée, était relativement modéré ${ }^{33}$.

Un autre travail féminin classique, s'occuper d'un ménage et d'enfants, fournissait à bon nombre d'émigrantes un complément. Une femme au foyer de Vienne, qui devait vivre seule à Bruxelles depuis qu'en mai 1940 son mari et son fils avaient été déportés vers la France, bénéficiait d'un logement dans une chambre meublée sans avoir à acquitter de loyer, et ce en aidant la famille du propriétaire dans les tâches ménagères ${ }^{34}$. D'autres gagnaient un peu d'argent en gardant les enfants de leurs logeurs. D'autres femmes encore tenaient le ménage de parents ou d'employeurs étrangers, ou trouvaient à s'occuper comme femmes de ménage ${ }^{35}$. Le travail comme employée de maison était dès avant l'occupation allemande, et tout comme aujourd'hui, une source typique de revenus pour des femmes réfugiées ${ }^{36}$.

Par exemple pour tricoter et ravauder : Kazerne Dossin, AJB, 21D, Service social, Rapports individuels, 166, 175.

33 AGR, Police des Étrangers, Dossiers individuels, A 337.008, voir I. Meinen - A. Meyer, op. cit., p. 48.

34 Interrogatoire d'Auguste B., 23.5.1941, DSK-Brüssel, Ceges, AA 585/53/2.

35 Voir par exemple : AGR, Police des Étrangers, Dossiers individuels, A 382.008, A 325.936, A 328.571, A 308.246. Rapport d'enquête DSK-Brüssel, 8.11.1940, Ceges, AA 585/53/2. Kazerne Dossin, AJB, 21D, Service social, Rapports individuels, 185.

36 Même alors ces domestiques étaient obligées de travailler illégalement (AGR, Police des Étrangers, Dossiers individuels, A 320.375, A 353.405) ; l'un ou l'autre avait un permis de travail (ibid., A 324.207). Voir aussi ce qu'a écrit Herta Stuberg-Wiesinger sur la période de son exil en Belgique et ses activités dans la Résistance (1938-1944), 1973 (dont des extraits furent reproduits dans Österreicher im Exil. Belgien 1938-1945. Eine Dokumentation, Dokumentationsarchiv des österreichisches Widerstandes, Wien, 1987). 
Enfin, quelques rares réfugiées gagnaient leur vie dans les secteurs de la restauration et de la prostitution. Des hommes qui avaient fui l'Allemagne servaient également dans des restaurants ou des bars comme garçons ${ }^{37}$. Cependant, ce n'est que pour les femmes qui avant leur fuite avaient été par exemple secrétaires ou gouvernantes et qui trouvaient à présent un emploi comme serveuses, racoleuses ou entraîneuses dans des tavernes ou des bars louches, que le travail fut lié au soupçon de prostitution ou, le cas échéant, à son exercice ${ }^{38}$. Ces femmes se retrouvèrent sous l'Occupation frappées d'une suspicion générale, car les médecins de la Wehrmacht de l'administration militaire soumettaient toutes les serveuses à un examen médical obligatoire de dépistage des maladies vénériennes. Et cela, qu'elles se soient contentées d'un rôle de serveuses et de racoleuses ou se soient effectivement livrées à la prostitution. Quoi qu'il en soit, dans ces branches également travaillaient des femmes qui gagnaient un revenu pour leur mari ${ }^{39}$.

Comme le montrent ces données sur l'activité des femmes venues d'Allemagne, les émigrantes exerçaient des travaux féminins traditionnels. Il s'agissait soit de métiers féminins, soit de travaux que les réfugiées réalisaient auparavant sans rémunération. Certaines d'entre elles s'engagèrent dans des activités dans d'autres domaines, par exemple comme illustratrice ou patronne de pension ${ }^{40}$. De plus, des femmes assumèrent au noir - ainsi que nous allons le voir - des commerces qui étaient tout sauf féminins.

\section{La situation particulière des réfugiés sous la pression des dispositions antijuives}

Avec le début de l'Occupation, les réfugiés juifs en Belgique ne perdirent en rien leur statut particulier. Au contraire, leurs conditions de vie et de travail continuèrent à se distinguer à bien des égards de celles

\footnotetext{
37 AGR, Police des Étrangers, Dossiers individuels, A 305. 092, A 329.093, A 317.870, A 293.728 .

38 Ibid., A 305.149, A 343.567.

39 Ibid., A 339.875, A 346.739. Sur le service sanitaire allemand qui poursuivait des femmes soupçonnées de prostitution, voir I. Meinen, Wehrmacht et Prostitution sous l'Occupation (1940-1945), traduit de l'allemand par Beate Husser, Paris, 2006.

40 AGR, Police des Étrangers, Dossiers individuels, A 307.447. Kazerne Dossin, Reliques Lilly Lustig. AGR, Police des Étrangers, Dossiers individuels, A 300.744.
} 
des Juifs autochtones. C'est ainsi que leur quotidien et leurs possibilités d'action demeurèrent marqués par une mobilité forcée qui avait commencé avec leur expulsion de l'Allemagne nazie. Poursuivis et expulsés avant 1940 par les autorités allemandes, les Juifs avaient souvent dû quitter précipitamment leur domicile dans le Reich allemand. En Belgique, où ils ne pouvaient d'abord pas travailler, la Police belge des Étrangers ne cessait de leur faire comprendre, non seulement à leur arrivée, mais encore durant les années de l'Occupation, qu'ils n'étaient tolérés qu'à titre transitoire dans le paysi1. À l'hiver 1940-1941, le commandant militaire allemand fit évacuer de force, par les autorités belges, les réfugiés juifs qui se trouvaient à Anvers vers la province belge de Limbourg, où certains d'entre eux furent mis au travail à Overpelt ${ }^{42}$. Le séjour au Limbourg fut limité et, au printemps suivant, on renvoya les réfugiés à Anvers ou, selon les cas, on les mit en demeure de trouver un logement à Bruxelles. Indépendamment de leurs effets épuisants, le statut de transitaire au cours des années et les changements de résidence plus ou moins fréquents posaient problème, compliquant considérablement le travail rémunéré des réfugiés. Sans compter un obstacle supplémentaire : les mesures antijuives du pouvoir allemand en Belgique.

\section{Candidats à la formation professionnelle}

Commençons par l'exclusion des Juifs des écoles et institutions $d$ 'enseignement. Les interdits d'enseignement successivement promulgués par l'administration militaire constituèrent deux étapes de

41 Beaucoup de cartes d'identité délivrées aux réfugiés portaient cette mention (par exemple: Kazerne Dossin, Reliques Szymon Blauner). De même ces réfugiés, que la Police des Étrangers contrôlait encore sous l'Occupation allemande, s'entendaient dire régulièrement qu'ils devaient quitter le pays dès que les circonstances le permettraient. Pour plus d'informations à ce sujet, voir I. Meinen - A. Meyer, op. cit., pp. 113-114.

42 La recherche a longtemps ignoré le fait que l'expulsion vers le Limbourg reposait sur l'ordre du Militärbefehlshaber (MBB), qui avait entre autres décidé le bannissement de toutes les personnes ayant quitté l'Allemagne pour la Belgique depuis 1933, de sécuriser la zone côtière. I. Meinen - A. Meyer, op. cit., p. 21. Sur le travail forcé à Overpelt, voir les exemples suivants: Kazerne Dossin, Reliques Bernard Bornstein, Reliques Bernard Damm, Reliques Hirsch Brodmann. Cf. La Belgique docile..., op. cit., pp. 452 453 (Seberechts). 
l'histoire de la persécution d'Erich Hälpern et de sa famille, que nous allons évoquer ci-dessous. Ce cas est l'un des nombreux exemples du fait de ce que les réfugiés ne cessaient de chercher de nouvelles possibilités d'embauche, même quand leurs efforts étaient restés vains. Erich Hälpern avait ainsi fui Vienne en 1939 avec ses parents. Lors de l'invasion allemande, il avait 15 ans $^{43}$. À Anvers, la famille reçut d'abord le soutien de l'organisation juive d'entraide EZRA (environ 80 francs belges par semaine $)^{44}$. Le père, qui avait été ouvrier textile en Autriche, trouva bientôt à Anvers une occupation, mais fut condamné en décembre 1939 par la justice belge pour travail illégal en tant que réfugié. À partir de juin 1940, la famille toucha de l'argent de l'aide sociale communale, jusqu'à son évacuation en janvier 1941 dans un petit bourg de la province de Limbourg. Lorsqu'elle put regagner Anvers trois mois plus tard, Erich Hälpern entama une formation professionnelle : il fréquenta l'école professionnelle de la ville pour devenir technicien automobile. Dès les années trente, la Belgique avait ouvert à beaucoup de jeunes réfugiés la possibilité d'une qualification scolaire et professionnelle. Le chef de l'administration militaire, par contre, exclut les réfugiés ainsi que les autres écoliers juifs des écoles belges ${ }^{45}$. Erich Hälpern fut donc contraint d'abandonner l'école professionnelle en avril 1942, avant d'avoir atteint le terme de son cursus de formation. Malgré cela, il n'abandonna pas ses efforts en vue d'apprendre un métier, et entama alors dans une firme d'Anvers un apprentissage de fourreur. Il commença par gagner 50 francs belges par semaine. De plus, la famille reçut à nouveau le soutien de l'aide sociale anversoise, tandis que le père - de même que quelques autres réfugiés - cherchait à obtenir des rentrées d'argent en se livrant au marché interdit de timbres de ravitaillement, jusqu'à ce que la police belge s'en rende

\footnotetext{
43 AGR, Police des Étrangers, Dossiers individuels, A 391.756.

44 Sur l'Ezra, voir L. Vloeberghs, « Ezra, een Antwerpse hulporganisatie voor Joodse transmigranten (1918-1940) », dans Les Cahiers de la Mémoire contemporaine, 10, 2011, pp. 77-109.

45 Ordonnance du 1.12.1941, Verordnungsblatt des Militärbefehlshabers in Belgien und Nordfrankreich (VOBIB), p. 801. Pour la mise en application de cette ordonnance, voir B. Dickschen, L'École en sursis. La scolarisation des enfants juifs pendant la guerre, Bruxelles, 2006.
} 
compte $^{46}$. Le même mois, mai 1942, la puissance occupante promulgua une ordonnance interdisant toute occupation de Juifs comme apprentis ${ }^{47}$. Elle empêcha Erich Hälpern de mener sa seconde formation professionnelle à bien et l'envoya dans le nord de la France, où il fut mis au travail obligatoire à l'été 1942 sur les chantiers du «Mur de l'Atlantique ». En octobre 1942, les Allemands déportèrent Erich Hälpern, à l'âge de 17 ans, de France à Auschwitz. Ses parents avaient déjà été transférés dans les premiers jours du mois au camp d'extermination. Aucun des trois ne survécut à la Shoah.

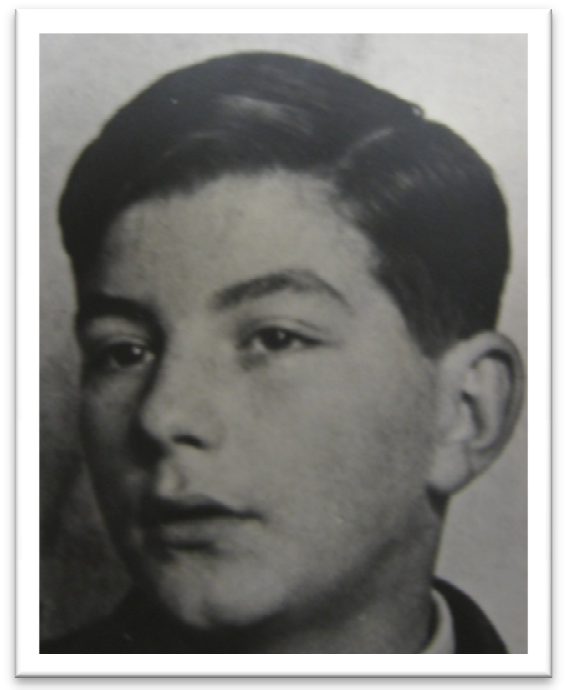

Erich Hälpern. (C) AGR

Certaines ordonnances du commandant militaire qui dépouillaient les Juifs de leur gagne-pain ou le leur rendaient difficile touchèrent moins le groupe des réfugiés que la population juive établie. Car nombre des fonctions et des activités rémunératrices à présent interdites aux Juifs avaient déjà été rendues inaccessibles aux réfugiés. L'exclusion du service public est un exemple probant à cet égard:

\footnotetext{
46 Pour plus d'exemples du trafic de timbres de ravitaillement : AGR, Police des Étrangers, Dossiers individuels, A 356.931, A 338.975.

47 Durchführungsverordnung zur Beschäftigung von Juden in Belgien, 8.5.1942, VOBIB, p. 911.
} 
certes le nombre des personnes concernées en Belgique était relativement restreint, du fait qu'une petite partie seulement des Juifs possédait la nationalité belge, mais pour les réfugiés l'ordonnance était totalement non pertinente ${ }^{48}$. Il en allait à peine autrement avec l'exclusion de l'économie de Juifs professionnellement actifs.

\section{Indépendants}

La majorité des Juifs vivant en Belgique était constituée d'immigrants arrivés pour la plupart d'Europe centrale et orientale après la Première Guerre mondiale et qui avaient bâti dans les années vingt et trente un tissu économique principalement constitué de petites entreprises familiales. L'économie typique des immigrés fut quasi totalement détruite par 1"“aryanisation" introduite à partir de 1941. Sous l'étiquette de « déjudaïsation de l'économie », l'occupant allemand en Belgique entendait presque exclusivement la mise à l'arrêt d'entreprises. Entre mars et mai 1942, ce ne sont pas moins de $83 \%$ de l'ensemble des 7.700 firmes données pour "juives" qui furent liquidées ${ }^{49}$. Selon l'estimation de Maxime Steinberg, le pionnier de la recherche sur la Shoah en Belgique, la fermeture des entreprises familiales retira à plus ou moins un tiers de la population juive de Belgique ses moyens économiques de subsistance ${ }^{50}$. Pour les Juifs autochtones, la liquidation forcée fut sans l'ombre d'un doute l'attaque la plus grave de l'occupant allemand contre leur existence matérielle.

Par contre, les réfugiés n'étaient parvenus que dans une très faible mesure à se construire une vie économique. Nous avons comparé les informations disponibles sur les firmes liquidées aux données person-

\footnotetext{
48 Sur le nombre de Juifs exclus de la fonction publique, voir M. Steinberg, La question juive..., pp. 36-37.

49 MBB, Militärverwaltungschef, Wi Gruppe XII, Abschlussbericht 16. Teil, « Treuhandvermögen », o. D. [1944], Bundesarchiv-Militärarchiv (Freiburg), RW 36/227. Voir Les Biens des victimes..., op. cit., pp. 82-94. Sur l'immigration des Juifs en Belgique, voir J.-Ph. Schreiber, « L'immigration juive en Belgique du Moyen Âge à nos jours », dans A. Morelli (dir.), Histoire des étrangers et de l'immigration en Belgique de la préhistoire à nos jours, Bruxelles 2004, pp. 215-242, ainsi que F. Caestecker, Ongewenste gasten..., op. cit., pp. 113-123.

50 M. Steinberg, La Persécution des Juifs en Belgique (1940-1945), Bruxelles, 2004, p. 215.
} 
nelles des Juifs qui avaient fui l'Allemagne nazie que nous avons rassemblées. La conclusion provisoire qui en découle est que les réfugiés géraient moins de $3 \%$ des entreprises juives en Belgique ${ }^{51}$. Comme l'atteste ce chiffre, leur proportion parmi les indépendants était minimale. La majeure partie d'entre eux travaillait dans le textile.

Les documents de la Police des Étrangers concernant Abram P. montrent que la fondation d'une entreprise ne pouvait la plupart du temps avoir lieu qu'en contournant les prescriptions du droit des étrangers. Ce maître-tailleur arriva en Belgique de manière illégale depuis Francfort-sur-le-Main au printemps 1939, après que la Gestapo l'eut interné durant deux mois et demi au camp de concentration de Buchenwald, puis expulsé du Reich allemand. Pour nourrir une famille de cinq personnes, il travailla en Belgique comme tailleur indépendant, bien que son activité lui ait à plusieurs reprises valu des ennuis de la part des autorités belges, jusqu’à ce que les Allemands ferment son commerce. En avril 1940, dès avant l'invasion allemande de la Belgique, la police belge le surprit en flagrant délit - il était justement sur le point de livrer un costume qu'il achevait - et dressa procès-verbal parce que Abram P. ne disposait pas de la carte professionnelle obligatoire $^{52}$. Introduite à la fin 1939, peu après le début de la guerre, pour permettre à l'État de contrôler le travail indépendant des immigrants, la carte professionnelle - et avec elle l'autorisation de mener une activité indépendante - n'était accordée que par exception aux étrangers, à moins qu'ils ne soient reconnus comme réfugiés politiques ou ne vivent légalement dans le pays depuis cinq ans au moins. Abram P. n’appartenait à aucune de ces catégories ; la majorité des réfugiés juifs d'Allemagne était dans le même cas.

Sous l'occupation allemande, il pouvait il est vrai exercer légalement sa profession, mais la gendarmerie belge constata à l'automne

\footnotetext{
51 Notre estimation est basée sur les listes d'époque des entreprises liquidées, qui sont conservées pour presque tous les secteurs économiques aux Archives générales du Royaume à Bruxelles (Archives du Séquestre de la BTG, 796-803). Nous avons déterminé l'identité de 4.068 propriétaires d'entreprise en premier lieu par une comparaison avec les Registres de Juifs (Kazerne Dossin). 119 d'entre eux (à peine $3 \%$ ) s'étaient enfuis de l'Allemagne nazie entre 1933 et 1938. Nous remercions chaleureusement Jörg Paulsen pour son aide dans l'élaboration de cette évaluation.

52 AGR, Police des Étrangers, Dossiers individuels, A 353.600.
} 
1940 que trois autres étrangers travaillaient comme tailleurs dans son entreprise, et ce sans posséder la carte de travail obligatoire à défaut de laquelle les étrangers ne pouvaient plus être employés comme salariés en Belgique ${ }^{53}$. Deux de ces trois hommes de l'atelier de P. - tout comme le propriétaire de l'entreprise lui-même - avaient fui au printemps la persécution des Juifs à Francfort-sur-le-Main, parmi lesquels un apprenti de 18 ans qui, selon le procès-verbal de la police, ne gagnait que 10 francs belges par semaine. Six mois plus tard, la police d'Anvers épingla à nouveau $P$., au motif qu'il pratiquait pour son tissu des prix excessifs et vendait en plus dans son magasin des articles de lingerie sans posséder la licence appropriée. La justice anversoise infligea une amende (pour usure prétendue et infraction au registre de commerce) au réfugié, qui avait entretemps déménagé à Bruxelles. Mais le coup décisif fut porté par l'administration militaire allemande, qui fit liquider l'entreprise au printemps $1942^{54}$. À la fin de l'été 1942, P. et sa femme furent arrêtés et, en 1943, la Gestapo déporta le couple à Auschwitz. Leurs trois enfants, nés à Francfort, furent accueillis dans un orphelinat de la communauté obligatoire (AJB) et survécurent en Belgique à l'occupation allemande.

À la différence d'Abram P., la plupart des réfugiés qui possédaient une firme établie en Belgique avaient immigré dès les premières années du régime nazi et obtenu un permis de séjour régulier. Ces Juifs précocement immigrés ne constituaient pourtant qu'une petite minorité parmi les réfugiés en Belgique occupée. Ce n'est qu'en 1938, après les grands pogroms, qu'avait commencé la fuite en masse des Juifs hors d'Allemagne. Par exception, on trouve dans les documents des indications sur des personnes qui obtinrent encore à cette époque un permis de travail, immigrèrent avec un visa et fondèrent légalement une entreprise en Belgique, que l'occupant liquida en 194255. La grande majo-

\footnotetext{
53 Sur les cartes de travail et les cartes professionnelles délivrées entre 1936 et 1939 , voir F. Caestecker, Ongewenste gasten..., op. cit., pp. 144-145, 259-260.

${ }^{54}$ Liste der zu liquidierenden Betriebe, I 28, AGR, Séquestre-BTG, 799.

55 Ernst Cleffmann, de Euskirchen, était un de ces fondateurs d'entreprise. En tant que spécialiste du secteur de la laine, il reçut, même après le pogrom de novembre 1938, un permis de travail et put ainsi obtenir officiellement une autorisation de séjour en Belgique début 1939, pour lui et pour son épouse. Il ouvrit à Jette (Bruxelles) un commerce de textile que l'administration militaire liquida au printemps 1942. Comme sa femme en témoigna à la police après la Libération, le couple perdit son domicile légal
} 
rité des réfugiés obtint en revanche une tolérance temporaire, à charge de n'exercer en Belgique aucune espèce d'activité économique. Dans son effort pour contrer la concurrence économique, l'administration belge gérait de manière restrictive la distribution des licences professionnelles. Même sous l'occupation allemande, alors que les réfugiés étaient mis en demeure de gagner leur vie par eux-mêmes, des licences leur étaient refusées.

Parmi ceux qui sollicitaient en vain une autorisation, figurait Kurt S., un lithographe et commerçant berlinois qui avait fui en 1939 vers les Pays-Bas et avait été expulsé en mai 1940 vers la Belgique. Début 1941, Kurt S. fit devant le Devisenschutzkommando, l'unité de police spécialisée dans la poursuite des Juifs et dans le vol de devises, la déclaration suivante à propos de ses moyens d'existence : "Début juin 1940, je suis arrivé à Bruxelles avec ma famille. Depuis lors, je suis chômeur. J'ai à l'occasion vendu des bijoux en or pour des joailliers moyennant commission. [...] En juin 1940, j'ai introduit une demande auprès de la Chambre belge de Commerce, d'autoriser mon commerce d'articles graphiques. Mais l'autorisation ne m'a pas été accordée. L'allocation qui m'a été accordée par les autorités belges ne suffisait pourtant pas à me faire vivre moi et ma famille, si bien que j'ai été obligé de vendre des bijoux appartenant à ma femme. » $^{56}$

En ce qui concerne la survie matérielle, l'indépendance ne constituait en rien une garantie d'être à l'abri de la pauvreté. Un certain nombre d'entreprises de réfugiés que l'administration militaire liquida en 1942 ne rapportaient guère plus à leur propriétaire ${ }^{57}$. S'il subsistait du capital lors de la liquidation forcée ou si l'entreprise était vendue à un propriétaire non juif, les fonds de caisse, dans la mesure où ils dépassaient 20.000 francs belges, étaient versés sur un compte bloqué. Si le fondateur de la firme avait possédé autrefois la nationalité alle-

et se cacha à Jette. Mais Ernst Cleffmann fut arrêté et déporté en juillet 1943. AGR, Police des Étrangers, Dossiers individuels, A 329.655 ; Liste der zu liquidierenden Betriebe, C 7, AGR, Séquestre-BTG, 796.

56 Interrogatoire de Kurt S., 6.1.1941, DSK-Brüssel, Ceges, AA 585/52/8.

57 Interrogatoire de Walter G., 4.2.1941 u. 22.5.1941, DSK-Brüssel, Ceges, AA 585/52/8; Vorbericht zur Vermögensmeldung Nr. I 26/1004, 20.11.1941, AGR, Séquestre-BTG, 781. La chute des revenus d'affaires à partir de mai 1940 ne toucha pas que les réfugiés, mais aussi beaucoup d'autres commerçants juifs, comme le montrent les documents conservés de la BTG. 
mande, il devait solliciter le déblocage auprès des instances allemandes pour assurer sa subsistance ou régler des dettes éventuelles ${ }^{58}$. Nous reviendrons, en conclusion de cet essai, sur les difficultés des réfugiés qui cherchaient à vivre de leurs propres ressources.

\section{Employés}

Certains ex-propriétaires qui fermaient leur commerce pouvaient au moins continuer à disposer d'une partie du capital de la firme. Il n'en allait pas de même des anciens employés, qui perdaient totalement leur revenu, dans la mesure où ils ne faisaient pas partie de la famille du propriétaire. On ne pourrait établir que sur base de recherches approfondies complémentaires dans quelle proportion des réfugiés étaient employés comme travailleurs salariés dans l'économie belge. Nous avons le sentiment que leur nombre doit également avoir été réduit, mais certains cas se présentaient tout de même. Nous avons évoqué plus haut l'exemple de la firme du tailleur Abram P., lui-même réfugié, qui employait plusieurs autres réfugiés. Dans des entreprises autochtones également, l'un ou l'autre réfugié pouvait avoir trouvé du travail 59 .

Le commerçant Wilhelm-Simon Hertz avait fui Cologne avec sa femme début 1939. En avril 1941, alors qu'il avait 26 ans, il obtint un emploi de manutentionnaire dans l'entreprise bruxelloise ParisBijoux $^{60}$. Ce commerce florissant de bijouterie de fantaisie, qui occupait à l'époque deux magasins dans le centre-ville, avait été fondé dans les années vingt par Emma Pollakova, une immigrée issue d'une famille juive de Prague. Hertz recevait un salaire mensuel de 850 francs belges. Mais, dès mai 1941, le commandant militaire promulgua les premières ordonnances antijuives dans le domaine économique, et $\mathrm{Pa}$ ris-Bijoux fut mis sous gestion d'un administrateur allemand, qui ven-

\footnotetext{
58 AGR, Séquestre-BTG, 3043, Dossier Ernst G. ; ibid., 3044, Dossier Gustav K. ; ibid., Dossier Siegfried K.

59 AGR, Police des Étrangers, Dossiers individuels, A 353.286 ; Séquestre-BTG, 698, Déclaration des biens Walter M. ; Kazerne Dossin, Reliques Grete Lederer.

${ }^{60}$ Kazerne Dossin, Reliques Wilhelm Simon Hertz. Sur cette chef d'entreprise, voir J. Misová Chmelíková, «L'émigration juive de Tchécoslovaquie en Belgique dans les années 30 et 40 du vingtième siècle », dans MuséOn, Revue d'art et d'histoire du Musée Juif de Belgique, 4, 2012, pp. 104-115, ici pp. 107-108.
} 
dit la firme à une personne non juive intéressée. Fin août 1941, quelques mois avant la naissance de son unique enfant, Hertz perdit son emploi. Son ex-patronne écrivit dans son certificat de travail : « Il perd son emploi à la suite de l'aliénation de l'entreprise par décision de l'autorité allemande et la rupture intempestive du contrat d'emploi par le cessionnaire. $»^{61}$ Deux ans plus tard, l'occupant déporta la famille Hertz à Auschwitz par le XXI' convoi.

\section{Travailleurs forcés}

L'occupant coupla l'exclusion des Juifs de l'économie à l'introduction du travail obligatoire. À la base de ces dispositions se trouvaient non seulement des motivations antisémites, mais aussi le besoin de main-d'œuvre de l'Organisation Todt (OT), ainsi que des considérations touchant la politique d'occupation. Entre juin et septembre 1942, les Allemands déportèrent dans le nord de la France, avec l'aide de l'administration belge du travail, plus de 2.000 hommes juifs, employés par l'OT à l'érection du «Mur de l'Atlantique »62. À l'automne 1942, Reeder, chef de l'administration militaire, livra les travailleurs forcés à la Sipo-SD aux fins de leur déportation à Auschwitz. Environ 1.550 d'entre eux furent déportés en trois grands groupes en octobre 1942. Il est à remarquer que les Juifs originaires du Reich allemand étaient sous-représentés parmi ces travailleurs forcés. D'après nos recherches, le nombre des réfugiés juifs d'Allemagne et d'Autriche parmi les victimes de la Shoah de Belgique atteignit au total $22 \%$. Des travailleurs forcés déportés du nord de la France à Auschwitz via Malines, $13 \%$ seulement étaient par contre des réfugiés juifs ${ }^{63}$.

61 Attestation signée par Emilie Pollakova, 3.9.1941, Kazerne Dossin, Reliques Wilhelm Simon Hertz.

${ }^{62}$ M. Steinberg, La persécution..., op. cit., pp. 215-221 ; voir I. Meinen, La Shoah en Belgique, op. cit., pp. 37-47.

${ }^{63} \mathrm{La}$ différence frappante de nombre change à peine si on limite la comparaison, dans le groupe des hommes valides parmi les réfugiés, aux travailleurs forcés convoqués par l'OT. De ce groupe, environ $23 \%$ ont été déportés à Auschwitz. Pour la proportion de réfugiés parmi les victimes de la Shoah en Belgique, voir I. Meinen - A. Meyer, op. cit., pp. 123-126, 151. Pour l'estimation du nombre de réfugiés parmi les travailleurs forcés, nous avons comparé les données personnelles que nous avons recueillies aux listes des 
Cette particularité pourrait avoir plusieurs explications. Parmi les nombreux Juifs qui refusèrent de donner suite à leur convocation pour le travail obligatoire, les réfugiés étaient-ils surreprésentés, comme c'était aussi le cas pour d'autres formes de résistance des Juifs en Belgique ?64 $\mathrm{Ou}$ bien des particularités régionales jouèrent-elles ici un rôle ? Le dernier point, à savoir le domicile des réfugiés, semble avoir été le critère le plus important. Comme nous avons pu le montrer ailleurs, la fuite de Juifs d'Anvers vers Bruxelles qui se produisit sous l'occupation allemande était plus marquée parmi les réfugiés d'Allemagne que parmi les Juifs autochtones, si bien qu'en fin de compte trois quarts de tous les réfugiés vivaient dans la capitale belge $^{65}$. La majorité des travailleurs forcés de l'Organisation Todt venait pourtant d'Anvers, vu que les autorités bruxelloises ne collaboraient que de manière limitée aux procédures de recrutement, alors que la police d'Anvers coopérait à la déportation de nombreux Juifs. En ce qui concerne les revenus des réfugiés mis au travail dans le nord de la France, on ajoutera que les travailleurs forcés de l'OT recevaient une rémunération qui contribuait dans certaines circonstances à l'entretien de leur famille restée au foyer ${ }^{66}$.

\section{Fuir le travail obligatoire}

Comment les Juifs réagirent-ils à la déportation qui menaçait? Leur marge de manœuvre était-elle fonction de leur situation de revenus? Comme le montre l'exemple suivant, la décision de se mettre à l'abri en plongeant dans la clandestinité pouvait coûter cher et mettre en danger la survie matérielle. Leo Baum et Lea Fiksel-Baum étaient

\footnotetext{
travailleurs forcés déportés à partir du Nord de la France vers Auschwitz, que nous a fournies aimablement Laurence Schram. Sur le nombre de travailleurs forcés déportés par les XVe, XVIe et XVIIe convois, voir W. Adriaens, M. Steinberg, L. Schram et al., Mecheln-Auschwitz, 1942-1944. La destruction des Juifs et des Tsiganes de Belgique, 1, Bruxelles, 2009, pp. 295-296.

${ }^{64}$ Cf. I. Meinen et A. Meyer, op. cit., pp. 149-150.

65 Ibid., pp. 144-145, 386, note 67.

66 Pour de plus amples renseignements, voir A. Godfroid, « À qui profite l'exploitation des travailleurs forcés juifs de Belgique dans le nord de la France? Modalités de payement et de rétrocession », dans Cahiers d'Histoire du Temps présent, 10, 2002, pp. 107128.
} 
nés en Autriche-Hongrie à la veille du siècle. Expulsés d'Allemagne après le pogrom de novembre, venus de Berlin, ils se réfugièrent au tournant de 1938-1939 à Anvers. Devant l'échec de leurs tentatives d'émigrer en Argentine ou en Palestine, les conjoints vécurent, sous l'occupation allemande, dans la ville de l'Escaut. En juin 1942, Leo Baum fut convoqué pour le travail obligatoire de l'Organisation Todt dans le nord de la France. Le couple déménagea alors d'Anvers et se fit inscrire dans la commune bruxelloise de Saint-Gilles. C'est là que le mari et sa femme eurent par la suite leur domicile officiel. On peut cependant se demander s'ils ont jamais réellement gagné leur nouveau domicile : au printemps suivant au plus tard, tandis que planait la menace de la déportation depuis le camp de Malines, ils vivaient en effet dans une cache à une adresse non communiquée à l'administration dans la commune de Bruxelles.

Leur fuite d'Anvers les confronta au problème vital d'avoir perdu leur source de revenus. Jusqu'à juin 1942, Lea Fiksel et Leo Baum, qui avait été colporteur à Berlin et avait provisoirement travaillé en Belgique dans l'agriculture, avaient été soutenus par l'Ezra, l'organisation juive anversoise d'aide aux candidats à l'émigration. À Bruxelles, par contre, ils n'avaient plus de revenus. Ils ne pouvaient pas prétendre à l'aide sociale communale, dès lors qu'ils vivaient dans la clandestinité. Ils durent donc se séparer peu à peu tout ce qu'ils possédaient et se serrer la ceinture en vendant une partie de leurs timbres de ravitaillement. Dans un rapport du Service social de l'AJB, on peut lire à quel point leur situation au printemps 1943 était devenue dramatique: «Mme B. est tuberculeuse par sous-alimentation; elle reçoit double ration, mais vend ses timbres pour pouvoir vivre. ${ }^{67}$ En dépit de ces circonstances, le couple, en fuite depuis 1939, parvint à échapper à ses persécuteurs allemands jusqu'en 1944. En avril 1944, la Gestapo déporta Lea Fiksel et Leo Baum à Auschwitz par le XXIVe convoi.

Un autre réfugié de 20 ans, qui habitait à Bruxelles avec ses parents malades et vivait d'allocations, refusa de rechercher du travail via l'Office du travail (Arbeitsamt), craignant de se voir, en tant que demandeur d'emploi, happé pour le travail obligatoire. Bien que le bu-

67 Kazerne Dossin, AJB, 21D, Service social, Rapports individuels, 173, Rapport du 4.5.1943; pour des informations complémentaires, voir ibid., Reliques Leo Baum; AGR, Police des Étrangers, Dossiers individuels, A 339.529. 
reau communal d'aide sociale eût mis la pression sur la famille à plusieurs reprises, qu'il eût exigé une déclaration de chômage ou un engagement et qu'il l'eût menacée de suspendre ses paiements, le jeune homme persista dans son attitude de prudence (l'aide sociale continua à être payée $)^{68}$. Afin de se faire exempter du travail obligatoire, d'autres réfugiés se procuraient, avec l'aide de l'Office du travail de Bruxelles, des attestations de travail authentiques ou falsifiées ${ }^{69}$. D'autres gagnèrent, tout comme certains Juifs de Bruxelles et d'Anvers menacés par la politique allemande de mise au travail, le bassin minier et industriel du sud de la Belgique et y trouvèrent un travail. Un ex-employé de banque de Vienne, qui cherchait depuis 1939 un refuge à Bruxelles, s'engagea comme ouvrier dans une cimenterie de Charleroi pour éviter d'être convoqué pour le travail obligatoire et fut néanmoins expédié de là sur les chantiers de l'OT dans le nord de la France ${ }^{70}$.

\section{L'importance des connaissances linguistiques : professions libérales et institutions juives}

Souvent immigrés peu avant l'Occupation, tolérés à titre temporaire et exclus du marché de l'emploi, les réfugiés adultes avaient tout juste eu l'occasion d'étudier l'une des langues pratiquées à Bruxelles ou à Anvers avant que l'invasion allemande en mai 1940 ne réduise à néant leurs perspectives d'émigration et ne les contraigne à trouver un emploi en Belgique. La méconnaissance du français et du néerlandais constituait un inconvénient dans la recherche d'un travail, comme l'atteste l'exemple suivant. Le marchand de tissu Isaak R., d'Halberstadt, s'exila en Belgique avec sa femme après le pogrom de novembre 1938. Au printemps 1942, il fut recruté de force à Anvers et expédié sur la côte atlantique dans le nord de la France, où il dut travailler pour l'entreprise allemande Heinrich Micka. En octobre 1942, la Sipo-SD le déporta à Auschwitz via Malines. Sa femme plongea dans la

\footnotetext{
68 Kazerne Dossin, AJB, 21D, Service social, Rapports individuels, 112.

${ }^{69}$ Ibid., Reliques Kurt Götzl.

${ }^{70}$ I. Meinen, “"Je devais quitter le pays dans les dix jours..." » (voir note 6), pp. 203204. Sur ceux qui ont fui vers Charleroi : A. Godfroid, « À qui profite... », op. cit. (voir note 66), pp. 110-111; La Belgique docile..., op. cit., pp. 470-477 (F. Seberechts).
} 
clandestinité. Avec son jeune enfant, elle gagna Bruxelles sans le signaler ni communiquer sa nouvelle adresse aux autorités. Pour subsister matériellement, elle commença par vendre ses bijoux ou d'autres objets de valeur. Au printemps 1943, ses ressources étant épuisées, elle s'adressa à l'Aide sociale de l'AJB pour obtenir un travail, de secrétariat par exemple, ou une allocation. Le bureau considéra d'emblée la demande d'emploi de Madame R. comme sans objet, «étant donné qu'elle ne parle qu'allemand $\aleph^{71}$. Nous ignorons comment la veuve gagna sa vie dans la suite, mais il est établi qu'elle-même et son enfant connurent la fin de l'occupation nazie.

\section{Journalistes, traducteurs, enseignants}

Il existait néanmoins des activités pour lesquelles la maîtrise de la langue allemande s'avérait utile, et quelques réfugiés saisirent cette chance, notamment dans les diverses professions libérales, ouvertes cependant qu'à une petite minorité des réfugiés. Il ressort des mouvements contemporains de migration que des réfugiés possédant une bonne formation se voient contraints de travailler en dessous de leur niveau de qualification ${ }^{72}$. L'exercice de ces professions libérales fait néanmoins partie des activités par le biais desquelles les Juifs expulsés d'Allemagne assurèrent leur subsistance en Belgique occupée.

L'écrivain viennois Max Hayek, de confession protestante, fut après l'annexion de l'Autriche poursuivi en tant que Juif, interné et expulsé. Il était veuf au moment d'arriver en Belgique au début 1939.

71 Kazerne Dossin, AJB, 21D, Service social, Rapports individuels, 154, Rapport du 30.4.1943.

72 Dans la littérature de l'exil, on trouve quelques informations sur les années trente. Lion Feuchtwanger, qui vécut en France entre 1933 et 1940, écrit : « So lebten also die deutschen Emigranten zumeist in Dürftigkeit. Es gab Ärzte und Rechtsanwälte, die mit Krawatten hausierten, Büroarbeit verrichteten, oder sonst wie, illegal, von der Polizei gehetzt, ihr Wissen an den Mann zu bringen suchten. Es gab Frauen mit Hochschulbildung, die als Verkäuferinnen, Dienstmädchen, Masseusen ihr Brot verdienten. » (« Les émigrés allemands vivaient ainsi le plus souvent dans l'indigence. Il y avait des médecins et des avocats qui colportaient des cravates, qui faisaient du travail de bureau ou bien qui, traqués par la police, cherchaient à utiliser leurs compétences en travaillant clandestinement. Il y avait des femmes diplômées de l'enseignement supérieur qui gagnaient leur vie comme vendeuses, servantes, masseuses. »). Cf. L. Feuchtwanger, Exil, Frankfurt a. M., 1979, p. 123. 
Comme il l'avait déjà fait à Vienne, d'après ce qu'il indiqua lui-même, il écrivit à Bruxelles pour des journaux suisses, anglais et américains ${ }^{73}$. Son espoir d'obtenir, sur base de ses contacts internationaux, un visa pour les États-Unis s'évanouit. Vivant à partir du printemps 1940 sous administration militaire allemande en Belgique occupée, il lui restait au moins son travail pour des organes de presse de la Suisse, un pays neutre, qu'il poursuivit manifestement encore plusieurs années durant. C'est en tout cas ce que permet de conclure le rapport d'un fonctionnaire de la Police belge des Étrangers qui auditionna Hayek au début mars 1944 en tant que témoin dans une procédure pénale belge et vérifia dans ce contexte sa situation de revenus : « L'apatride Hayek, Max, [...] résidant à Schaerbeek, rue Vandermeersch, $\mathbf{n}^{\circ} 47$, écrivain, occupe là seul une chambre garnie, dont il paie régulièrement la location. Il vit pauvrement et ses revenus sont minimes, mais il ne bénéficie d'aucun secours officiel. Il tire sa subsistance d'articles non politiques qu'il fournit à la presse suisse, principalement au journal Baseler Zeitung et parfois à des périodiques belges, tel Anne-Marie, revue de mode. [...] Il passe la plupart de son temps à la Bibliothèque royale, où il puise les éléments qu'il développe dans ses articles. Il y passe surtout son temps parce qu'il y fait plus chaud que chez lui. s $^{74}$

Lorsque l'occupant appréhenda l'écrivain Max Hayek deux mois plus tard, il portait sur lui, outre sa carte de presse établie en 1939, une carte de lecteur de la Bibliothèque royale. Il fut déporté à Auschwitz le 19 mai 1944, à l'âge de 61 ans, par le XXVe convoi. Moins les réfugiés disposaient d'argent pour leur nourriture et leur chauffage, plus important s'avérait l'accès à un lieu de séjour supportable. C'est aussi pour cette raison pratique que la Bibliothèque s'avéra une véritable oasis pour un certain nombre d'intellectuels parmi les réfugiés. L'écrivain Jean Améry parle déjà, se référant à son exil à Anvers dans l'avantguerre, d'« une salle de bibliothèque bien chauffée, qui était infiniment plus accueillante qu'une chambre sinistre dans un hôtel douteux $»^{75}$. À l'époque où est rédigé ce rapport, il n'y avait assurément plus d'endroit accueillant pour les Juifs. Leur souci principal était désormais

\footnotetext{
73 AGR, Police des Étrangers, Dossiers individuels, A 340.600. En Belgique, d'autres réfugiés travaillèrent également pour des journaux étrangers, ibid., A 330.038.

${ }^{74}$ Ministère de la Justice, Police des Étrangers, Rapport, 8.3.1944, ibid., A 340.600.

75 J. Améry, Örtlichkeiten, Stuttgart, 1980, p. 44.
} 
d'échapper aux Allemands qui les chassaient, lesquels pouvaient surgir de partout.

Depuis 1943, ceux-ci concentraient leur recherche d'hommes, de femmes et d'enfants juifs sur Bruxelles, où s'était entretemps établie la grande majorité des réfugiés. La recherche historique s'en est longtemps tenue à l'affirmation correcte de Maxime Steinberg que deux tiers - et par là la majeure partie - des victimes de la Shoah en Belgique avaient été déportées dès l'année 1942. Néanmoins, pour Bruxelles, cette affirmation ne tient pas: pas moins de la moitié de tous les Juifs déportés de Bruxelles ne furent arrêtés, tel Max Hayek, que dans les années 1943 ou $1944^{76}$.

Ce ne sont pas seulement des hommes, mais également des femmes qui mirent à profit leur connaissance de la langue allemande pour en tirer de quoi vivre en Belgique occupée. Anna K. avait émigré en 1933 de Berlin en Belgique avec sa famille. En mai 1940, elle devint veuve, parce que l'aviation allemande bombarda des convois en direction de la France et, à cette occasion, toucha un train par lequel l'administration belge évacuait vers la France des ressortissants allemands en âge de porter les armes, parmi lesquels, outre quelques nationaux-socialistes, se trouvaient beaucoup de réfugiés juifs. Le mari d'Anna K. faisait partie des victimes. En août 1942, Anna K. fournit des éclaircissements à propos de son travail et de ses revenus dans une lettre adressée à l'administration militaire allemande (Anmeldestelle für Jüdisches Vermögen), sollicitant le déblocage de son compte immobilisé par l'occupant: «Mon mari a été interné le 10 mai par les autorités belges en tant que citoyen allemand et est mort à Ath le 13 mai dans le convoi à destination de la France suite à un bombardement. Je travaille depuis lors comme traductrice et professeur d'allemand pour pouvoir me nourrir moi et mon enfant mineur. Comme je dois m'acquitter régulièrement de factures (loyer, gaz, électricité, etc.), je me suis ouvert ce compte-chèques postal. »77 $\mathrm{Il}$ y eut quelques Juifs allemands qui effectuèrent des traductions afin de se faire un revenu ${ }^{78}$.

\footnotetext{
${ }^{76}$ I. Meinen - A. Meyer, op. cit., pp. 145-146.

77 Lettre d'Anna K., 26.8.1942, AGR, Séquestre-BTG, 3044, Dossier Anna K.

${ }_{78}$ Rapport de la Police de Bruxelles, 3. div., 23.10.1940, AGR, Police des Étrangers, Dossiers individuels, A 335.982 ; Demande de ratification d'une cession de comptes de
} 
Quand Anna K. travaillait comme professeur d'allemand, il se peut qu'elle ait donné cours à des enfants d'autres réfugiés. Anna K. et sa fille mineure échappèrent à l'arrestation par la Gestapo en Belgique.

\section{Médecins}

Tout comme dans les mouvements migratoires actuels, la fuite massive des Juifs dans les années trente impliquait un besoin d'activités pratiques couvert par les réfugiés eux-mêmes et générait un revenu. Un exemple en est fourni par les réfugiés qui travaillaient dans la Belgique d'avant-guerre en tant que passeurs et venaient en aide aux Juifs lors de leur entrée illégale sur le territoire ${ }^{79}$. Des indépendants qui avaient fui l'Allemagne continuaient à offrir sous l'occupation allemande des services en langue allemande, dont dépendait le groupe des réfugiés, qui constituait entre 1940 et 1944 près du quart de la population juive de Belgique. Parmi eux, les membres du corps médical. De manière comparable à la réglementation en vigueur dans le Reich, le commandant militaire frappa à partir de juin 1942 tous les médecins juifs d'une interdiction professionnelle, mais permit à une série d'entre eux, par autorisation spéciale, de traiter exclusivement des Juifs. Le docteur Otto H., qui avait émigré en septembre 1938 de la région d'Aix-la-Chapelle vers la Belgique, était l'un de ces médecins autorisés pour la population juive. Au printemps et à l'été 1943, il gagnait officiellement selon son compte en banque quelque 1.200 francs belges par mois en moyenne ${ }^{80}$. Il pratiqua au moins jusqu'octobre 1943 comme médecin indépendant à Bruxelles. Cela n'allait pas sans danger, car même les médecins autorisés avaient un statut totalement incertain. La section Médecine à l'état-major de Reeder, le chef de l'administration militaire, qui était chargée de statuer sur l'autorisation des Juifs à exercer les professions de santé, était dirigée par des médecins qui s'employaient activement à promouvoir la déportation des Juifs. C'est ainsi que la section Médecine proposa par exemple à la Sipo-SD de déporter de Bruxelles des médecins juifs

titres et de soldes de trésorerie juifs bloqués, 3.6.1942, AGR, Séquestre-BTG, 3044, Dossier Ernst K.

${ }^{79}$ I. Meinen - A. Meyer, op. cit., pp. 69-70, pp. 153-186.

80 AGR, Séquestre-BTG, 3044, Dossier Otto H. 
qu'elle désigna nommément. Elle en informa l'Oberfeldkommandantur de Bruxelles dans une lettre de la mi-octobre 1942: "On informe de plus en toute discrétion que, des médecins autorisés jusqu'ici, 15 ont disparu, 5 ont été expédiés, que 15 autres médecins juifs et 11 dentistes ont été proposés au SD pour être expédiés. »81 Parmi les médecins évoqués ici, qui quittèrent leur logement officiel à Bruxelles avant la mioctobre 1942 parce qu'ils étaient passés dans la clandestinité ou avaient été arrêtés, pas moins de sept étaient des réfugiés d'Allemagne nazie $^{82}$. Otto $H$. conserva son logement, et il ne fut pas victime de la « solution finale ». Autre réfugié de formation médicale : le Berlinois Fritz Basch, qui travaillait après son arrestation comme médecin au camp de transit de Malines, jusqu’à sa déportation en $1943^{83}$. La rémunération du médecin du camp incombait à la communauté obligatoire des Juifs en Belgique (AJB), qui était pour sa part financée par des contributions forcées modulées en fonction des revenus.

\section{Employés des institutions juives}

Le cantor Gabriel Rosenbaum, originaire de Pologne, avait fui Berlin pour gagner la Belgique en novembre 1938, après les grands pogroms. Sous l'occupation allemande, évacué d'Anvers au Limbourg et renvoyé dans la métropole quelque temps plus tard, il bénéficia de

81 Gruppe Medizin (Hördemann) à l'OFK 672, 12.10.1942, concernant un centre de consultation de tuberculose pour les Juifs à Bruxelles, Archives nationales (Paris), AJ 40/57, Dossier la. Sur d'autres initiatives antijuives des services médicaux allemands, voir I. Meinen, «Les autorités allemandes d'occupation et l'AJB », dans J.-Ph. Schreiber - R. Van Doorslaer (dir.), Les curateurs du ghetto..., op. cit., p. 73.

82 Dr. Paul Lutz, Verwaltungsbeauftragter, « Bericht über den Besuch von Wohnungen jüdischer Ärzte », 8.10.1942, Archives Nationales, AJ 40/57, Dossier 1a. Parmi les médecins répertoriés dans cette liste se trouvent, sous les numéros 5, 7, 10-13, 15, des réfugiés d'Allemagne; parmi eux, le médecin berlinois Alfred Galewski, déporté en 1943 par le XXIII ${ }^{e}$ convoi et qui a survécu à la Shoah. La liste mentionne aussi le Dr Maximilian Samuel. S'étant enfui vers la Belgique après le pogrom de novembre à Cologne, il essaya de nouveau en 1942 de se mettre hors de portée des Allemands en s'enfuyant et parvint dans le sud de la France. Il fut arrêté près de la frontière suisse, interné à Belfort et déporté de France le 31 août 1942 par le XXVIe convoi. S. Klarsfeld, Mémorial de la Déportation des Juifs de France, Paris, 2012, p. 579.

83 Voir Maxime Steinberg, La Traque des Juifs 1942-1944, vol. II (L'Étoile et le fusil, T. 3), Bruxelles, 1986, p. 197. 
l'aide sociale publique. À partir de mai 1941, il sera, comme nombre d'autres réfugiés, mentionné comme journalier au fichier de l'Office du travail d'Anvers, sans jamais obtenir d'emploi. À partir du début 1942, la Police des Étrangers exigea la prise d'un travail rémunéré et fit pression régulièrement sur Rosenbaum, y compris après que celui-ci eut, en mai, quitté Anvers pour Bruxelles-Schaerbeek. Fin juin 1942, il put enfin satisfaire aux exigences des autorités belges. Il pratiquait à présent son métier de cantor dans les synagogues bruxelloises. D’après ses propres déclarations, son revenu hebdomadaire se montait à 150 francs belges, tandis son logement lui coûtait 150 francs par mois. Toujours est-il qu'il gagnait comme cantor $50 \%$ de plus que ne lui avait versé l'aide sociale ${ }^{84}$. Il ne put poursuivre son travail que quelques mois. En octobre 1942, l'occupant déporta Gabriel Rosenbaum à Auschwitz à l'âge de 49 ans.

Pour quelques réfugiés, le travail au sein d'une organisation juive offrait l'unique possibilité de satisfaire aux exigences de la Police des Étrangers. C'est ainsi que la communauté obligatoire des Juifs de Belgique (AJB) ne fournit un emploi à la mi-1942 à plusieurs Juifs réfugiés d'Allemagne que parce que la Police des Étrangers subordonnait la relaxe de ces étrangers de la détention administrative à l'obtention d'un certificat d'emploi ${ }^{85}$. Indépendamment de cela, une série de réfugiés allemands travaillaient dans l'administration de l'AJB et dans les institutions qu'elle gérait. Certains occupaient des postes subalternes, par exemple comme cuisinière ou fille de cuisine à la cantine sociale d'Anvers, d'autres exerçaient des fonctions dirigeantes, par exemple dans l'aide sociale ${ }^{86}$. Ainsi, le professeur Jonas Tiefenbrunner dirigeait l'orphelinat juif, rue des Patriotes à Bruxelles, et l'éducatrice Rosa Kugelman le Joods Weeshuis (orphelinat juif) à Anvers. Tous deux avaient fui l'Allemagne vers la Belgique en 1938.

84 AGR, Police des Étrangers, Dossiers individuels, A 328.441. Cette description correspond à la situation en novembre 1941 .

85 I. Meinen - A. Meyer, op. cit., pp. 110-113.

${ }^{86}$ Liste du personnel du comité local de l'AJB d'Anvers, cuisine populaire, 30.8.1942, Kazerne Dossin, A 002914.23. Parmi les employés ici mentionnés se trouvent au moins deux réfugiés (Lotti Fingerhut et Otto Wolf). Tous deux furent déportés ; Lotti Fingerhut survécut à la Shoah. Pour les informations suivantes, voir : ibid., A 002914.33; Judenregister ; J.-Ph. Schreiber - R. Van Doorslaer (dir.), Les curateurs du ghetto..., op. cit., pp. 284, 308 . 
En tant que locuteurs natifs de l'allemand, les réfugiés étaient tout particulièrement prédestinés aux tractations avec les services allemands. Ils n'étaient nullement les seuls à assumer cette tâche, mais purent prétendre à une place de plus en plus prépondérante dans ce domaine à partir du printemps 1942, lorsque l'AJB créa un bureau central pour les interventions auprès des autorités d'Occupation, bien qu'il en ait résulté des conflits entre eux et les membres belges de la direction de l'AJB. En cause ici, les ordres et le modus operandi des persécuteurs allemands. Ce sont surtout les représentants d'Eichmann à Bruxelles qui privilégiaient des Juifs germanophones comme contacts responsables de la communauté obligatoire en Belgique ${ }^{87}$.

\section{Avocats}

Parallèlement au bureau d'intervention de l'AJB, de rares réfugiés exerçaient en indépendants les fonctions d'avocat et représentaient les intérêts de Juifs allemands et autres devant les autorités d'Occupation $^{88}$. La parfaite maîtrise de la langue de l'occupant constituait pour eux aussi la condition sine qua non de leur gagne-pain. Le juriste berlinois Alfred H., membre avant la Seconde Guerre mondiale de la Chambre de Commerce belgo-allemande, pouvait, en 1939 encore, entrer en Belgique légalement, compte tenu de ses contacts avec les cercles économiques belges. Il motiva sa demande d'immigration par un projet de fondation d'une entreprise relativement importante, que le Ministère belge de l'Économie considéra comme avantageux pour l'économie belge. C'est ainsi que lui et sa femme obtinrent l'autorisation de s'installer en Belgique ${ }^{89}$. Il se peut qu'il ait programmé ce projet commercial purement et simplement parce que la création de pareille entreprise était l'une des dernières possibilités qui

${ }^{87}$ I. Meinen, « Les autorités allemandes d'occupation et l'AJB », dans J.-Ph. Schreiber - R. Van Doorslaer (dir.), Les curateurs du ghetto..., op. cit, pp. 65, 68-70. Voir aussi dans le même volume la contribution de J.-Ph. Schreiber, « Entre communauté traditionnelle et communauté obligatoire », pp. 98-100.

${ }^{88}$ L'un d'eux était le Dr. Bernhard Spitz, qui avait fui l'Allemagne en 1938 et qui en 1940 avait émigré des Pays-Bas vers la Belgique. Il fut déporté par le Convoi XXIIa en 1943. Lettre du Dr. Bernhard Spitz au Chef Mil.verw., Wi Gruppe XII, 29.5.1942, AGR, Séquestre-BTG, 3044, Dossier Lilli H.

89 AGR, Police des Étrangers, Dossiers individuels, A 341.774. 
s'offraient encore en 1939 d'obtenir un visa d'entrée. En tout cas, il est clair que $H$. ne vint pas en Belgique pour des raisons professionnelles, mais qu'il devait fuir l'Allemagne en raison de la persécution des Juifs. En 1942 au plus tard, il exerçait en Belgique occupée en tant qu'avocat de réfugiés juifs allemands; à l'occasion, des Juifs autochtones le consultèrent également.

La politique antijuive de l'occupant généra le besoin d'un soutien juridique de la part de réfugiés juifs. L'avocat Alfred H. s'adressa ainsi à la section économique de l'administration militaire (Groupe XII et Treuhandgesellschaft de Bruxelles) pour obtenir l'accès à des avoirs sociaux bloqués ou, dans d'autre cas, faire ajourner ou empêcher la liquidation programmée d'une entreprise ${ }^{90}$. Il lui arrivait aussi de traiter avec des fonctionnaires allemands et de leur remettre des pots de vin en vue d'obtenir la libération de Juifs arrêtés. Il doit avoir bénéficié d'un accès privilégié auprès de membres de l'appareil d'Occupation, vu que la section économique de Reeder finit par le désigner comme l'un de ses nombreux administrateurs d'entreprises à propriétaire juif, tout incompatible que cela fût avec son origine juive ${ }^{91}$. Les administrateurs étaient rémunérés sur les fonds des propriétaires juifs. À en croire la déclaration après-guerre de l'ex-chargé des affaires juives de la SipoSD de Bruxelles, Felix Weidmann, la Gestapo de Berlin ordonna en novembre 1943 l'arrestation de H. en faisant valoir qu'un Juif ne pouvait être employé par un service allemand. H. fut arrêté par Weidmann en personne et déporté à Auschwitz en avril 1944 par le XXIVe convoi.

Il survécut à la Shoah et revint en Belgique. D'après la constatation de l'Auditorat militaire belge, qui poursuivit $H$. après la Libération à la requête d'autres réfugiés juifs allemands, son activité en tant qu'administrateur n'a en rien donné lieu à des plaintes de la part des intéressés. Le juriste fut plutôt accusé d'avoir détourné des pots de vin

\footnotetext{
90 AGR, Séquestre-BTG 2515, 2261, 3044 (Dossier Ernst K.), 3043 (Dossier Ernst G.), 3045 (Dossier Paul M.), 3046 (Dossier Georg S.).

91 Selon ses dires, non vérifiables, il était l'ami du fils du banquier et ancien ministre de l'Économie Hjalmar Schacht, qui dirigeait prétendument le département d'espionnage économique de l'Abwehr de Bruxelles.
} 
et d'avoir dénoncé des Juifs à la Gestapo ${ }^{92}$. Après-guerre, la justice belge suspendit les recherches par manque de preuves, d'autant plus que H. contestait les préventions. Il fut pourtant expulsé du pays par la Police belge des Étrangers. L'histoire trouble de l'activité de ce réfugié montre une fois de plus que l'aide à d'autres Juifs et le travail pour l'occupant étaient couramment susceptibles d'interférer sous la domination nazie, même si l'on ne peut dire avec certitude que $H$. alla jusqu'à dénoncer des Juifs.

Toutes les prestations pour les autorités allemandes furent loin de déboucher sur de la complicité avec les crimes nazis. Car le quotidien de l'Occupation en Europe occidentale offrait nombre d'activités qui n'eurent aucune incidence sur le déroulement de la « solution finale » ni sur d'autres atrocités commises par les Allemands en Belgique. Les multiples prestations de services et offres de marchandises pour les membres des services allemands, qui disposaient d'amples moyens financiers et dépensaient sans compter, sont à cet égard typiques. Certains réfugiés se firent un peu d'argent ou gagnèrent leur vie dans ce domaine, où leurs compétences linguistiques en allemand constituaient sans nul doute un atout. Les exemples qui apparaissent dans les documents vont des blanchisseurs de chemises et ramasseurs de quilles pour soldats de la Wehrmacht aux tailleurs pour employés des chemins de fer allemands. Le plus répandu était le marché noir.

\section{Le travail illégal : commerce ambulant, marché noir, activités inter- médiaires}

Début août 1940, quelques mois après le début de l'occupation allemande, un caporal de la Feldkommandantur d'Anvers se présenta dans un commissariat de police pour dénoncer un civil qu'il amena personnellement aux fonctionnaires belges ${ }^{33}$. Tous deux, le plaignant comme l'accusé, firent leur déposition en langue allemande. Mais, alors que l'un représentait le régime nazi, l'autre faisait partie de ceux qu'il persécutait : Peisach Baruch Geller, un travailleur de 36 ans, qui avait fui Vienne au début de l'année précédente et devait rester en Belgique,

\footnotetext{
92 Le procureur de la Cour militaire de Bruxelles à l'Administrateur de la Police des Étrangers, 1.3.1947, AGR, Police des Étrangers, Dossiers individuels, A 341.774.

93 AGR, Police des Étrangers, Dossiers individuels, A 336.663.
} 
après que ses efforts pour émigrer aux États-Unis eurent échoué. Son crime? Il avait proposé en rue, dans le centre d'Anvers, à son compatriote d'acheter une tablette de chocolat au lait. Vu que Geller avait agi sans licence comme marchand ambulant, le tribunal anversois compétent lui infligea une amende, ou à défaut 15 jours d'emprisonnement.

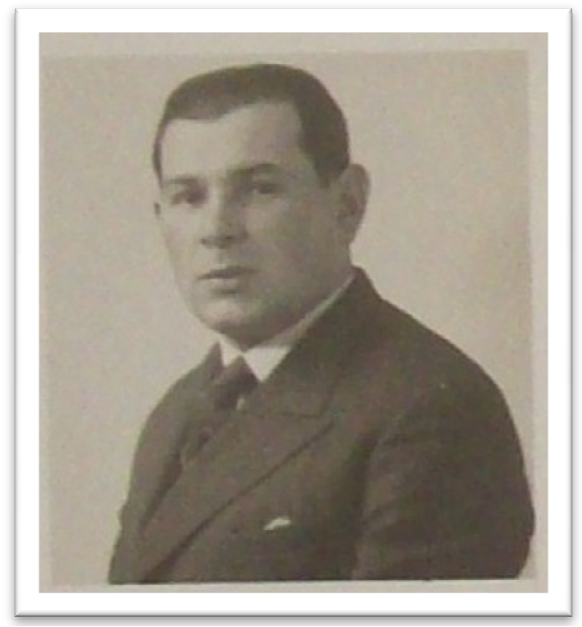

Peisach Baruch Geller. (C) AGR

Il semble que Geller commerçait à petite échelle et à son propre compte. Selon les investigations de la police anversoise, il avait acquis le chocolat dans une épicerie locale - en tout deux ou trois tablettes de 330 grammes chacune - et cherché à le vendre pour 18,5 francs. Son profit était de 3,5 francs la tablette. La police ne trouva d'autres fournitures ni dans le commerce en question ni au domicile de Geller. Luimême ne portait par ailleurs sur lui que deux paquets de café.

Un an et demi plus tard, la police de Bruxelles contrôla à nouveau Geller, en même temps que vingt-huit autres étrangers, dans un café de Saint-Josse. Tous étaient soupçonnés de marché noir. Comme les preuves concrètes faisaient défaut et que les contacts de Geller avec les forces de l'ordre belges restèrent cette fois sans suite, nous ne savons pas s'il assura à plus long terme sa subsistance au moyen de trafics. 
Reste qu'il vécut dans le pays jusqu'en avril 1944, quand la Sicherheitspolizei allemande le déporta à Auschwitz par le convoi ${ }^{\circ}$ XXIV.

\section{Des jeunes, des vieux et des femmes colporteurs}

L'écolier Otto Bellak avait fui Vienne en compagnie de ses parents et de ses deux frères. Il n'avait pas 16 ans lorsque la police d'Anvers le trouva le $1^{\text {er }}$ décembre 1940 en train de vendre en rue, en plein Anvers, des cigarettes de marques diverses à des soldats allemands. Grâce à son admission dans une école anversoise, et à la différence de nombre de réfugiés adultes, il pouvait s'exprimer en langue néerlandaise. « Je savais, déclara-t-il, qu'il n'était pas permis de colporter sans autorisation, mais je l'ai fait par pauvreté et je n'ai pas de carte de colporteur » («Ik wist dat het niet toegelaten was te leuren zonder toelating, doch ik heb gedaan uit armoede en ben niet in bezit van een leurkaart ») ${ }^{94}$. Les autorités anversoises renoncèrent à punir le jeune garçon. En 1942, l'occupant le déporta à Auschwitz, lui et toute sa famille.

Si même des adolescents cherchaient à vendre en rue, sans autorisation, des friandises et du chocolat, c'est imputable au fait que cette activité n'exigeait ni compétences préalables ni grands efforts, ni capital. Il s'agissait d'une solution typique pour gagner sa vie chez les réfugiés pauvres de toutes classes d'âge. Il y avait des Juifs chassés vers la Belgique par le régime nazi qui se voyaient contraints, à plus de 70 ans, de survivre de cette manière ${ }^{95}$. Ces caractéristiques font en outre du colportage une source de revenus fréquente chez les femmes. En fait, et ceci appartient aux résultats les plus remarquables de nos recherches biographiques, bon nombre de femmes ayant fui l'Allemagne pour la Belgique travaillaient comme marchandes ambulantes ${ }^{96}$. Elles contribuaient ainsi à l'entretien de leur famille, pour autant qu'elles ne fussent pas les seules à gagner un salaire. Marjem AltmannHofstaedter, une femme au foyer de Wiesbaden, qui cherchait depuis

\footnotetext{
94 Document de la Police d'Anvers, 6e division, 1.12.1940, AGR, Police des Étrangers, Dossiers individuels, A 327.441.

95 Jugement de l'OFK 672 (Brüssel) contre Abram Berberich, 6.8.1942, SVG, Dossiers judiciaires de la prison de Saint-Gilles, 0092.

96 Voir par exemple : AGR, Police des Étrangers, Dossiers individuels, A 355.354, A 308.124, A 361.023, A 342.805, A 366.309.
} 
juillet 1939 refuge à Bruxelles avec son mari, avait, quelques mois avant l'attaque de la Wehrmacht, pu récupérer son fils, qu'elle avait d'abord envoyé aux Pays-Bas. Début mars 1941, la jeune femme de 34 ans fut arrêtée par la police municipale dans le centre de Bruxelles parce qu'elle avait proposé du chocolat sans autorisation professionnelle à des soldats allemands. Elle se vit infliger une amende ${ }^{97}$. La situation matérielle de la famille restait précaire. L'année suivante, l'administration militaire allemande expédia le père au travail obligatoire dans le nord de la France. De son salaire, une partie seulement fut payée à Marjem Altmann-Hofstaedter, qui couvrait à peine les frais de loyer et de chauffage. Elle en était réduite à ce que son frère lui envoie d'Amsterdam une contribution à son entretien. En 1943, mère et fils furent victimes de la Shoah.

\section{Les risques du travail illégal : dénonciation et sanctions}

Les cas évoqués révèlent l'un des problèmes que posait le petit commerce illégal : celui qui n'avait pas de chance tombait, en cherchant des clients, sur un membre des forces d'occupation, qui tentait justement de mettre un terme aux activités des commerçants ambulants. En même temps, il fallait échapper aux patrouilles de la police communale, qui prit en flagrant délit nombre de colporteurs et colporteuses issus du milieu des réfugiés. Il arrivait de surcroît, comme déjà avant l'Occupation, que d'autres étrangers ou civils belges dénoncent des réfugiés travaillant au noir - que ce soit pour des raisons de concurrence, de jalousie ou dans l'intérêt du bien commun ${ }^{98}$. Le 9 mai 1941, par exemple, une rentière belge attira l'attention de la police bruxelloise sur une femme qui, à l'instar d'autres réfugiés, se postait à un point de rassemblement de militaires allemands pour trouver un client ${ }^{99}$. La femme vendait devant une école militaire réquisitionnée

\footnotetext{
97 Ibid., A 362.180. Pour les informations suivantes, voir : ibid., Séquestre-BTG, 3043, Dossier Isaac A.

98 Sur la dénonciation du travail illégal (marché noir, travail à domicile ou emploi) avant l'Occupation : AGR, Police des Étrangers, Dossiers individuels, A 102.866, A 311.177, A 345.397, A 352.456.

99 Document de la Police de Bruxelles, 5e division, 13.5.1941, AGR, Police des Étrangers, Dossiers individuels, A 362.055.
} 
par les Allemands des tissus, du poivre et du chocolat. Mère célibataire, sans emploi, elle avait fui l'Allemagne et avait un fils en bas âge. Dans son cas, un sursis lui fut accordé. Quand il s’agissait de réfugiés sans casier judiciaire, les autorités belges ne réagissaient pas à des infractions similaires de manière draconienne. Si l’on ne renonçait pas simplement aux poursuites, celles-ci se concluaient par une amende légère, qui constituait néanmoins pour de pauvres colporteurs une charge supplémentaire.

En ce qui concerne l'autorité occupante, son traitement du marché noir se calquait prioritairement sur sa volonté de pillage économique sans vergogne de l'Europe occidentale occupée. Lors de leurs achats à petite ou à grande échelle, les Allemands - qu'il s'agisse d'envoyés du plan quadriennal de Goering ou d'autres bureaux du Reich ou d'unités d'Occupation et de soldats - recouraient massivement au marché noir et contribuaient de la sorte à ce que celui-ci prenne des proportions gigantesques. Outre aux commerçants concernés, le profit allait à l'économie de guerre allemande, au personnel du régime d'Occupation et à la population allemande, tandis que la plupart des Belges souffraient de manque suite à la pénurie et à la hausse exorbitante des prix, les conséquences pour le pays occupé étaient désastreuses, d'autant plus que les achats allemands s'effectuaient d'ordinaire sur le budget national belge ${ }^{100}$. Cet état de fait n'exclut pas que l'administration militaire, DSK ou Sipo-SD, contrôlait également le commerce au noir et poursuivait un certain nombre de fraudeurs. C' est ainsi qu'il arrivait à la Feldgendarmerie de dénoncer des colporteurs à la police belge ${ }^{101}$. Exceptionnellement, le commerce illégal de chocolat pouvait entraîner l'incarcération au camp de concentration de Breendonk par la Sipo-SD ${ }^{102}$. Plus fréquemment, les tribunaux militaires allemands infligeaient des amendes administratives.

100 Pour un aperçu général du marché noir allemand en Belgique occupée, voir L. Nestler (dir.), Die faschistische Okkupationspolitik in Belgien, Luxemburg und in den Niederlanden (1940-1945). Dokumentenauswahl und Einleitung, Berlin 1990 (= Europa unterm Hakenkreuz, Bd. 4), pp. 49-52, ainsi que E. Verhoeyen, La Belgique occupée, Bruxelles, 1994, pp. 215-227.

101 Police judiciaire de Bruxelles, rapport, 13.9.1941, AGR, Police des Étrangers, Dossiers individuels, A 338.798.

102 AJB, service d'interventions, note concernant Mendel K., 2.6.1942, Kazerne Dossin, AJB, Interventions, 260. (Dans ce cas, il ne s'agit pas d'un réfugié allemand.) 
L'exemple qui suit est édifiant en ce qu'il permet de porter son regard sur l'organisation de la strate inférieure de l'économie de l'ombre, dont il est question dans le contexte qui nous retient. Comme il apparaît par ailleurs, des réfugiés ne se livraient pas seulement au petit commerce: certains d'entre eux gagnaient également de l'argent comme revendeurs ou intermédiaires ${ }^{103}$. C'est ainsi que Maria P., 45 ans, qui avait fui Cologne pour Bruxelles en 1939 et travaillait comme femme de ménage, recrutait des clients allemands pour un autre réfugié lorsqu'elle tomba en novembre 1943 sur des agents du Devisenschutzkommando. Dans le jargon nazi dont usait ce corps de police, les faits sont décrits comme suit: «Am 26. November 1943 wurden der Feldw. [...] u. der Gefr. [...] vom D.S.K. auf der Straße von der Jüdin Maria P., wohnhaft in Brüssel [...], angesprochen. Sie bot Zigaretten und Kantinenwaren an, die der Volljude Samuel N., Brüssel [...], im Schwarzhandel verkauft. [...] Der Jude wurde aufgesucht und es stellte sich heraus, daß er vornehmlich Geschäfte mit deutschen Soldaten macht. »104 (« Le 26 novembre 1943, le sergent [...] et le caporal [...] du DSK furent abordés en rue par la Juive Maria P., résidant à Bruxelles. Elle leur proposa des cigarettes et des articles de cafeteria que le Volljude Samuel N., Bruxelles, écoule au marché noir. [...] On perquisitionna chez le Juif et il se vérifia qu'il fait principalement des affaires avec des soldats allemands. ») Le réfugié Samuel N., assistant de tailleur de pierre et expulsé de Berlin en décembre 1938, admit, lors de son audition par le DSK, qu'il se livrait au marché noir de cigarettes et de papier et que le plus gros de ses marchandises était en franchise. Ses clients étaient des soldats allemands, qu'il abordait lui-même en rue. Maria P. s'était proposée pour lui recruter des clients. De surcroît, N. avait officiellement livré à la Wehrmacht. Un caporal qui, dans le cadre de ses fonctions, rachetait en Belgique des rations militaires, lui avait entre autres commandé 13.000 cigarettes, qu'il avait obtenues. Dans ce cas, Samuel N., ainsi qu'il le déclara lui-même, avait compté 20 FB par boîte; ses prix oscillaient sinon entre 12,50 et 15 francs. Dans les deux cas, les occupants achetaient de manière illégale des cigarettes en

103 Parmi les intermédiaires figurent également des femmes : AGR, Police des Étrangers, Dossiers individuels, A 364.108.

104 Rapport de la DSK-Brüssel, 26.11.1943, Ceges, AA 585/88. 
grande partie non déclarées, ce que tout un chacun pouvait constater à l'absence de vignette fiscale.

Lors de son interrogatoire, N. finit par indiquer aux enquêteurs du DSK le nom de sa source de revenus. Son fournisseur Leo K. avait, tout comme N., fui l'Allemagne et la persécution des Juifs en 1938. Comme K. le déclara pour sa part, il avait gagné un temps sa vie en Belgique comme musicien et, depuis son mariage avec une Belge en 1940, il effectuait surtout des petits travaux pour son beau-père, et se livrait accessoirement au commerce de cigarettes. Selon ses propres déclarations, il avait entre autres livré à N. 150 boîtes au prix de 9 francs belges chacune et gagné lui-même 2 francs belges par boîte. Il n'indiqua pas auprès de qui il s'était lui-même procuré les marchandises.

Le tribunal de l'Oberfeldkommandantur de Bruxelles condamna Samuel N. et Leo K. en juin 1944 à des amendes et confisqua le stock de 7.000 cigarettes trouvé au domicile de K. Le fait que les deux réfugiés échappèrent à la déportation à Auschwitz est sans doute dû à leur mariage relativement précoce avec une non-Juive ${ }^{105}$. Depuis que les trains de la mort partaient de Belgique pour l'Europe de l'Est sous domination allemande, c'est-à-dire depuis la mi-1942, le contact avec les occupants allemands impliquait pour presque tous les Juifs le danger immédiat d'être arrêtés et déportés. Mais la subsistance matérielle devant être assurée, il y eut encore en 1942 et 1943 des réfugiés qui gagnaient leur vie en faisant des affaires avec les Allemands. Certains d'entre eux tombèrent de la sorte aux mains des sbires d'Eichmann.

\section{Travail illégal et déportation}

Le jeune Viennois Bela Grützmann arriva seul en Belgique à l'âge de 19 ans après l'annexion de l'Autriche à l'Allemagne hitlérienne en 1938. Dans les années qui suivirent, il renseigna comme professions tapissier et cordonnier, sans que nous sachions s'il a jamais exercé ces métiers ${ }^{106}$. Il changea plusieurs fois de domicile et, selon ses propres

\footnotetext{
105 Les Juifs qui avaient fait des mariages mixtes étaient, comme dans le Reich allemand, protégés de la déportation, à moins que les autorités d'occupation ne considèrent qu'il s'agisse d'un mariage de convenance.

106 AGR, Police des Étrangers, Dossiers individuels, A 307.991.
} 
déclarations, résida aussi temporairement dans le nord de la France. En octobre 1941, il fut rayé d'office à Bruxelles, car il n'avait pas fait prolonger son permis de séjour depuis le printemps, probablement parce qu'il avait dû renoncer à son logement. En novembre 1941, la police de Bruxelles constata en tout cas qu'il résidait dans la ville sans domicile, sans travail et sans moyens de subsistance. Elle l'interna donc à la colonie pour sans-abris de Merksplas en Flandre. Sur le site de cet asile traditionnel pour vagabonds s'était également établi avant l'occupation allemande un centre d'accueil pour réfugiés, où Grützmann avait à l'époque vécu plus d'un an. Il réintégrait à présent Merksplas en tant que vagabond. Cinq mois plus tard, en avril 1942, il s'en échappa.

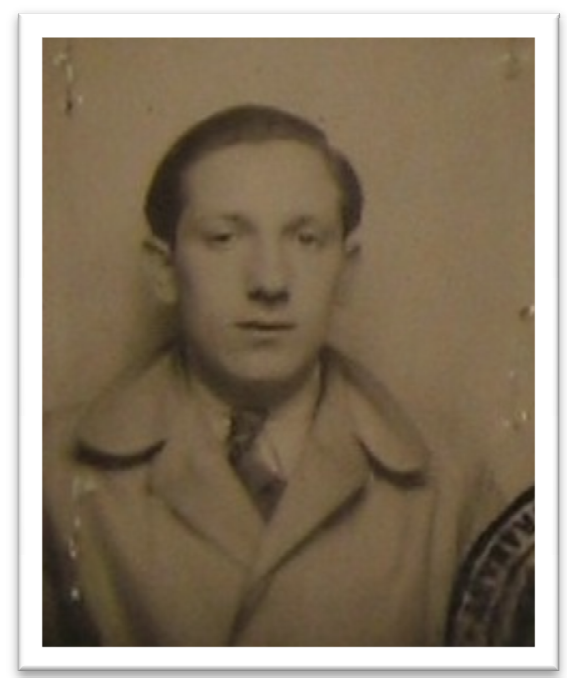

Bela Grützmann. (C) AGR

À Bruxelles, où il était illégal, il se procura de quoi vivre en abordant en rue des militaires allemands pour les emmener faire des achats dans des magasins choisis. Il s'agissait d'un travail à la commission, avec lequel des réfugiés d'Allemagne pouvaient gagner sous 
l'occupation allemande 3 à $10 \%$ du montant de chaque achat ${ }^{107}$. Dans ce cas, c'est un commerçant belge qui dénonça la transaction illégale et signala le démarcheur en juin 1942 à deux Feldgendarmes allemands. Un policier bruxellois exécuta l'ordre de ces Feldgendarmes d'amener Grützmann au poste, après avoir appris que ce dernier s'était échappé de Merksplas. La Feldgendarmerie interna le réfugié viennois à la prison de la Wehrmacht de Saint-Gilles. Cinq semaines plus tard, les autorités d'Occupation entamaient la déportation à Auschwitz. En accord avec l'administration militaire, la Sipo-SD vint chercher Bela Grützmann dans sa prison en octobre 1942 et le déporta à l'âge de 23 ans par le XIVe convoi.

Ces circonstances sont atypiques à maints égards. En effet, il était rare que des réfugiés soient internés dans une colonie pénitentiaire pour vagabonds sous l'occupation allemande. Et surtout, ce fut une exception que la police de Bruxelles collabore avec des services de police allemands lors de l'arrestation de Juifs ${ }^{108}$. Il est par contre caractéristique que des réfugiés se voient contraints de travailler de manière illégale, alors qu'en Europe occidentale occupée des règles particulières régissaient l'autorisation des activités rémunératrices. Tandis que les maîtres allemands achetaient au noir, non seulement en privé, mais aussi dans l'exercice de leurs fonctions, et à cette fin requéraient entre autres les services de réfugiés juifs, la vente restait illégale en droit belge et pouvait en outre être poursuivie par les autorités allemandes. Par ailleurs, la réglementation antijuive du commandant militaire allemand avait pour conséquence que des réfugiés juifs se retrouvent passibles de sanction, alors même qu'ils observaient toutes les dispositions belges.

Leopold Wachs, un représentant de commerce qui avait fui Vienne en 1939, fut employé pendant deux ans après l'invasion de la Wehr-

${ }^{107}$ C'est ce que signalent les enquêtes belges dans un cas similaire, rapport de la Police de Bruxelles, 2. Div., 30.1.1941, AGR, Police des Étrangers, Dossiers individuels, A 339.015 .

$108 \mathrm{Si}$ dans le rapport de recherche La Belgique docile..., op. cit., une autre analyse est proposée, il s'agit d'informations erronées, incompatibles avec les sources belges et allemandes conservées. Voir en détail à ce sujet : I. Meinen, « Why the Belgian Perspective Cannot Account for the Holocaust : A Response to Lieven Saerens' Critique of My Book on the Shoah in Belgium », dans Journal of Belgian History, XLIII/4, 2013, pp. 213-230, ici pp. 226-230. 
macht dans une brasserie bruxelloise fréquentée par les troupes d'Occupation ${ }^{109}$. C'est alors que l'administration militaire allemande introduisit l"“étoile jaune". Wachs n'appartenait pas à la communauté religieuse juive, mais l'idéologie raciale nationale-socialiste fit de lui un Juif et il se trouva de ce fait soumis à l'obligation de porter l'étoile. Il ne pouvait dès lors plus travailler dans la brasserie. On peut supposer que Wachs n'était pas le seul à perdre son salaire suite à l'ordonnance du commandant militaire. L'introduction de l'"étoile juive", par laquelle l'État nazi accentua la stigmatisation sociale et l'enregistrement policier, entraîna donc, comme le montre cet exemple, de lourdes conséquences pour la situation matérielle des Juifs. En septembre 1942, arrêté sur base de la dénonciation par un sous-officier de la Wehrmacht pour n'avoir pas porté l'insigne et condamné par les juges militaires à une peine d'emprisonnement, Wachs réussit après sa relaxe à trouver un nouvel emploi, qui restait cependant incompatible avec le port de l'étoile. Il redevint tout d'abord portier, puis démarcha en rue des soldats de la Wehrmacht pour les inviter à se rendre dans la brasserie où il avait travaillé auparavant. Il portait sur lui une lettre officielle de la police belge au terme de laquelle le bourgmestre de Bruxelles avait autorisé dans la première quinzaine de juin 1943 la distribution de dépliants publicitaires. En droit belge, Wachs travaillait donc légalement; en droit allemand, il travaillait illégalement, à savoir sans l'insigne. On ne peut guère préciser s'il fut arrêté dans le cadre de son travail avec le personnel du régime occupant ou durant son temps libre. En tout cas, il fut, à la même époque (le 10 juin 1943 au plus tard), conduit de Bruxelles à Malines et inscrit sur la liste du convoi suivant, qui quitta Malines le 31 juillet 1943. Wachs ne revint pas d'Auschwitz.

\section{La présence de réfugiés dans l'économie de l'ombre}

Nous nous sommes jusqu'ici contentée de cerner une portion réduite du commerce au noir sous l'occupation allemande. Le spectre des biens

\footnotetext{
109 SVG, Dossier SDR Leopold Wachs; Kazerne Dossin, Reliques Leopold Wachs ; voir aussi I. Meinen - A. Meyer, « Le XXIe convoi : études biographiques (deuxième partie) », dans Les Cahiers de la Mémoire Contemporaine, 8, 2008, pp. 35-98, ici pp. 3738.
} 
illégalement trafiqués était sensiblement plus vaste, et concernait toute la gamme des produits disponibles. On dispose dans l'un ou l'autre cas de preuves que dans diverses branches du marché noir travaillaient - entre autres personnes - des réfugiés en provenance de l'Allemagne nazie. Ils commerçaient à leur propre compte, travaillaient à la commission pour des tiers ou servaient d'intermédiaires entre vendeurs et acheteurs potentiels. Ce dernier cas pouvait impliquer le démarchage de clients pour un vendeur, dont nous avons déjà décrit les méthodes. Cela pouvait aussi signifier de récolter et échanger des informations relatives à qui cherchait ou souhaitait vendre quel produit. Ces activités d'intermédiaires étaient inévitables pour les transactions effectuées secrètement. Elles n'offraient à vrai dire souvent qu'un (maigre) emploi d'appoint, si bien qu'elles devaient être combinées à d'autres petits travaux, mais présentaient l'avantage de pouvoir être exercées par des personnes sans moyens ${ }^{110}$. Dans la mesure où il y allait de marchandises précieuses comme des bijoux ou des liquidités, il s'agissait pour ces réfugiés, la plupart du temps paupérisés, d'une activité intermédiaire ou d'un mandat, bien plus que d'un commerce autonome.

L'occupant n'était pas toujours impliqué, mais des commerces au noir sans participation allemande directe pouvaient indirectement le concerner ou faire son affaire. C'est ce que montre l'exemple d'un fourreur échappé d'Allemagne, qui gagna à partir de 1941 sa vie et celle de ses parents par l'importation illégale de France en Belgique de déchets de fourrure et fournissait entre autres un artisan qui produisait des vestes en cuir pour la Wehrmacht ${ }^{111}$. C'est ce que montre aussi le change illégal de devises, issues entre autres des achats au noir par des membres des forces d'Occupation, qui payaient fréquemment en billets du Reich, qu'il était interdit et poursuivi par le DSK d'accepter en territoire occupé. Ceux qui trafiquaient en noir à la sauvette avec des Allemands devaient donc parfois trouver aussi quelqu'un pour changer en sous-main en francs belges l'argent allemand inutilisable. Il en va de même du change de francs belges en devises étrangères, dont les réfu-

\footnotetext{
110 Interrogatoire de Kurt S., 6.1.1941, DSK-Brüssel, Ceges, AA 585/52/8 ; interrogatoire de Joseph K., 20.5.1942, DSK-Brüssel, ibid., AA 585/110 ; AGR, Police des Étrangers, Dossiers individuels, A 346.739.

111 Ceges, AA 585/53/7.
} 
giés eux-mêmes étaient tributaires, parce que, même sous domination nazie, ils tentaient encore de fuir la Belgique, sinon l'Europe occidentale occupée et avaient donc besoin de francs français, de dollars américains, etc. ${ }^{112}$

Il ne fait aucun doute que le marché noir offrait, entre autres aux Juifs qui n'avaient quitté l'Allemagne que peu avant l'Occupation, des possibilités de revenus. Certains documents peuvent même laisser supposer que la proportion de réfugiés parmi ceux qui se livraient au petit trafic atteignait un niveau dépassant la moyenne. Ainsi la police communale de Saint-Josse-ten-Noode (Bruxelles) adressa un rapport à l'administrateur de la Police belge des Étrangers au début 1941 : « J'ai l'honneur de vous faire connaître que les étrangers ci-après ont été identifiés, le 23 janvier dernier, entre 10 et $13 \mathrm{~h}$., sur la voie publique et dans les cafés situés rue des Croisades et du Marché. Ces individus sont tous soupçonnés de se livrer clandestinement au commerce ambulant. Ils ont donné des explications fantaisistes pour justifier leur présence, maintes fois constatés aux abords de la gare du Nord. Ils accostent principalement les militaires et les personnes au service de la Wehrmacht. $»^{113}$

Parmi les treize hommes étrangers nommément mentionnés dans ce document, pas moins de la moitié avait fui l'Allemagne avant-guerre à cause de la persécution antijuive et des pogroms, ainsi qu'il ressort de notre comparaison avec les dossiers individuels à la Police des Étrangers.

Un an plus tard, en mars 1942, la police communale contrôla lors d'une rafle dans un café de la même rue 29 étrangers qui, d'après les constatations des fonctionnaires belges, s'y réunissaient pour s'adonner au jeu et trafiquer des denrées rationnées ${ }^{114}$. Au moins 22 de ces 29 immigrants (à nouveau exclusivement des hommes), étaient des réfugiés juifs d'Allemagne nazie - parmi eux Peisach Geller, mentionné cidessus. Si l'on veut comprendre ces rapports, il convient de savoir que les réfugiés en question n'avaient pas été identifiés par hasard : dans la

112 Ibid., AA 585/53/6 ; AA 585/54/1 ; AA 585/52/5 ; 585/52/2 ; AA 585/54/6.

113 Police de Saint-Josse-ten-Noode à l'Administrateur de la Police des Étrangers, 31.1.1941, AGR, Police des Étrangers, Dossiers individuels, A 339.174.

114 Police de Saint-Josse-ten-Noode à l'Administrateur de la Police des Étrangers, 31.3.1942, AGR, Police des Étrangers, Dossiers individuels, A 336.663. 
même petite rue à proximité de la gare du Nord, la police belge avait effectué des rafles dès 1938, dans le but, à cette époque, de mettre la main sur des réfugiés illégaux ${ }^{115}$. En 1941 et 1942, elle prospectait donc méthodiquement des endroits connus comme points de rencontre de réfugiés, avant de distinguer parmi eux les marchands à la sauvette. Mais le dossier était si lacunaire que la Justice belge n'intenta aucune procédure contre les hommes mis en cause. Pourtant, les inculpations policières avaient un arrière-plan concret, d'importance pour notre sujet: furent en effet soupçonnés de marché noir des réfugiés dans l'incapacité de fournir, lors de l'interrogatoire, quelque justification satisfaisante à l'origine de leurs revenus.

\section{Revenus d'origine indéterminée}

Benjamin E., né en 1901 à Czernowitz, voyageur de commerce et employé de profession selon ses dires, dut fuir l'Autriche en mai 1938116. La Police belge des Étrangers l'expulsa après avoir appris que, bien avant l'avènement du régime nazi, il avait été condamné à plusieurs reprises pour escroquerie, jeu de hasard prohibé, séjour illégal, etc., et avait été expulsé d'Autriche comme apatride. Comme Benjamin E. ne donnait pas suite à l'expulsion de Belgique, il fut arrêté plusieurs fois, mais vivait toujours à Bruxelles lorsque la Wehrmacht occupa la capitale. Lui-même, sa femme avec laquelle il s'était marié religieusement et leurs deux enfants nés en Belgique reçurent d'abord le soutien de l'aide sociale publique. Au plus tard, en 1941, Benjamin E. se mit en quête d'une activité professionnelle. En tant que représentant d'une firme belge, il vendit du matériel de bureau à des entreprises dans la zone de Bruxelles. Il exerça aussi, en même temps ou par la suite, le même travail à son compte. À partir du début 1942, il ne put plus, à cause de la pénurie provoquée par l'occupant, se procurer de marchandises. Sa femme, qui mit au monde en mai leur troisième enfant, perçut à nouveau brièvement l'aide sociale.

Il expliqua lui-même à la Police des Étrangers, qui ne cessait de lui réclamer des renseignements sur ses sources de subsistance, qu'il avait

\footnotetext{
115 Arrondissement Bruxelles, Police judiciaire, rapport, 28.4.1938, AGR, Police des Étrangers, Dossiers individuels, A 292.030.

116 AGR, Police des Étrangers, Dossiers individuels, A 300.574.
} 
hérité de son frère des bijoux et des vêtements, les avait vendus et s'était ainsi procuré un revenu, sans pouvoir en apporter la preuve. La Police supposait qu'il se livrait au marché noir de textiles, d'autant plus que, lors des rafles de mai 1942 dont il a été question plus haut, elle l'avait surpris et avait repéré dans son misérable logement de modestes stocks de textiles neufs et usagés (32 chemises pour homme et pour femmes, etc.). Ce soupçon ne put être étayé. Dans la première quinzaine d'octobre 1942, les autorités d'Occupation arrêtèrent dans le nord de Bruxelles, où habitait Benjamin E., des Juifs pour le XIIIe convoi à destination d'Auschwitz ${ }^{117}$. Benjamin E. comptait parmi eux et fut déporté le même mois. Sa femme fut victime de la Shoah l'année d'après. Leurs trois enfants survécurent au nazisme en Belgique.

Il y a en fait beaucoup de cas pour lesquels la manière dont des réfugiés assurèrent leur existence matérielle sous occupation allemande reste obscure. On ne peut déterminer l'importance de la proportion de ceux qui subsistèrent en recourant au commerce au noir. Pour le formuler de manière synthétique, nos recherches indiquent que les réfugiés étaient la plupart du temps actifs dans le segment inférieur du commerce au noir. Le petit marchand itinérant, un emploi classique de pauvre, en est caractéristique. Dès avant l'Occupation, des réfugiés furent à l'occasion interpellés par la police belge pour avoir fait du porte-à-porte avec des marchandises modestes (tissus, crayons, etc.) (118 $^{18}$ Dans l'intérêt des colporteurs belges, l'État belge gérait l'octroi d'autorisations de colportage aux immigrants d'Allemagne de manière restrictive depuis le milieu des années trente ${ }^{119}$. En Belgique occupée également, cette politique fut poursuivie, bien que les réfugiés fussent à présent tenus de travailler ${ }^{120}$. En même temps, il y avait désormais

117 Nous avons relevé les adresses des déportés du XIIIe convoi mentionnées dans les Registres des Juifs élaborés pendant l'Occupation et comparé avec la date d'enregistrement de chacun au camp de transit de Malines. Un bon nombre d'entre eux ont été inscrits dans les communes du nord de Bruxelles, Schaerbeek et Saint-Josse. Cf. I. Meinen, La Shoah en Belgique, op. cit., p. 182.

118 AGR, Police des Étrangers, Dossiers individuels A 290.077, A 292.030, A 336.045, A 348.013. Le colportage non autorisé pouvait entraîner l'expulsion de Belgique (ibid., A 290.076). Voir aussi note 98.

119 F. Caestecker, Ongewenste gasten..., op. cit., pp. 136-148.

120 Dans le cadre de nos recherches sur les entreprises dirigées par des Juifs qui furent liquidées à partir de 1942 (voir note 52), nous n'avons trouvé jusqu'à présent que trois 
beaucoup plus de débouchés, parce qu'avec le personnel de l'appareil d'Occupation existait un tout nouveau groupe de clients solvables. Dans la mesure où des Juifs expulsés du Reich allemand se décidaient à faire affaire avec leurs ex-compatriotes représentant le régime nazi, ils pouvaient tabler sur leur connaissance de la langue et de la mentalité allemandes.

\section{Excursus : frais de subsistance et revenus en Belgique occupée, 1940- 1944}

Lorsque Joseph Roth quitta son exil parisien dans les années trente pour vivre quelque temps en Belgique, il le fit entre autres, selon ses propres dires, parce que son argent s'épuisait ${ }^{121}$. L'écrivain expulsé par les nazis menait certes un train de vie relativement onéreux et devait de surcroît s'occuper de sa femme qui requérait des soins. Mais d'autres réfugiés venaient également explicitement en Belgique parce que le royaume était « connu comme un pays où des réfugiés pouvaient vivre à bon compte $»^{122}$. En comparaison avec l'Autriche ou la France, un communiste autrichien réfugié constatait encore a posteriori qu'on pouvait « y vivre à très bon marché $~^{123}$. On sait que la situation matérielle de la majorité des habitants du pays empira graduellement sous l'occupation allemande. On peut cependant se demander de quels moyens on avait réellement besoin pour vivre en Belgique occupée,

réfugiés juifs qui détenaient une licence pour le commerce ambulant en Belgique. Deux d'entre eux étaient des femmes.

121 Le 15 juin 1936, Joseph Roth annonça à Stefan Zweig, dans une lettre écrite à Amsterdam, son voyage à Bruxelles, en ajoutant : « Ich werde in Brüssel wahrscheinlich noch einsamer sein, als hier, aber besser und länger auskommen können. » (« À Bruxelles, je serai probablement encore plus seul qu'ici, mais je peux m'en sortir financièrement mieux et plus longtemps. »). Le 8 août 1936, il écrit d'Ostende : « Ich bin genau mit 1800 belgischen Francs für drei Monate hier hergegangen, ich muss im billigsten Land sein... » (« Je suis arrivé ici avec exactement 1.800 francs belges pour trois mois, je dois être dans le pays le moins cher... »), dans M. Rietra et R. J. Siegel (éds.), «Jede Freundschaft mit mir ist verderblich». Joseph Roth und Stefan Zweig. Briefwechsel 1927-1938, Göttingen, 2011, pp. 324, 344.

122 Formulaire : « Questions à poser aux étrangers qui se déclarent réfugiés politiques » : réponse de l'agent commercial Max K. à la question de savoir pourquoi il avait fui vers la Belgique, 2.5.1938, AGR, Police des Étrangers, Dossiers individuels, A 291.630. 123 Österreicher im Exil. Belgien 1938-1945, op. cit., p. 68. 
ainsi que dans quelle mesure les revenus et les ressources des réfugiés suffisaient pour y pourvoir.

Les montants de l'aide sociale communale offrent un premier repère. Il est vrai que leurs allocations varient considérablement : c'est non seulement le nombre de personnes composant la famille qui est déterminant, mais aussi l'appréciation de chaque cas particulier et la durée de l'allocation. Toutefois la somme usuelle pour des femmes seules d'âge moyen se chiffrait à 450 francs belges par mois environ. Il fallait compter au moins 50 francs pour le logement, ce qui correspond à la catégorie de prix inférieure pour une chambre meublée. Une petite mansarde coûtait environ 100 francs. Beaucoup de familles de réfugiés payaient des loyers entre 200 et 300 francs, auxquels s'ajoutaient les charges. Si l'on jette un coup d'œil au tableau des prix des denrées alimentaires ci-contre, il est patent qu'un montant de 450 francs suffisait à peine pour survivre. Les rapports conservés du service social de l'association obligatoire des Juifs en Belgique (AJB) le confirment également. Quand quelqu'un ne touchait que 450 francs, qu'il n'était ni aidé par un tiers ni ne disposait de ressources propres, il avait besoin d'indemnités ou de biens de consommation supplémentaires ${ }^{124}$.

Les rémunérations les plus modestes de réfugiés, que nous connaissons par les documents individuels et que nous avons partiellement déjà mentionnés, correspondaient au niveau de cette aide sociale. Les aides-cuisinières, gardes d'enfants et nettoyeuses gagnaient environ 500 francs; les apprentis encore moins. Les tailleurs à domicile percevaient entre 400 et 700 francs; un emploi de manutentionnaire ou de magasinier dans une entreprise rapportait 700 à 1.000 francs $^{125}$. Ce n'est que dans trois cas exceptionnels que nous avons trouvé des indications de revenus mensuels de plus de 1.000 francs (un médecin : 1.200 francs, deux tailleurs: 1.300 et 1.800 francs respectivement) ${ }^{126}$.

\footnotetext{
${ }_{124}$ Kazerne Dossin, AJB, 21D, Service social, Rapports individuels, 168, 162, 131.

125 Les salaires des employés de l'association pour les réfugiés, qui avait été fondée par des émigrants juifs allemands, s'élevaient aussi à 1.000 francs. Rapport sur l'entretien avec le comité de la rue de Ruysbroeck, 27.3.1942, PV du comité directeur de l'AJB, séance du 26.3.1942 (annexe), SVG, R497/Tr146.665.

126 AGR, Police des Étrangers, Dossiers individuels, A 331.028 ; Ceges, AA 585/54/13.
} 


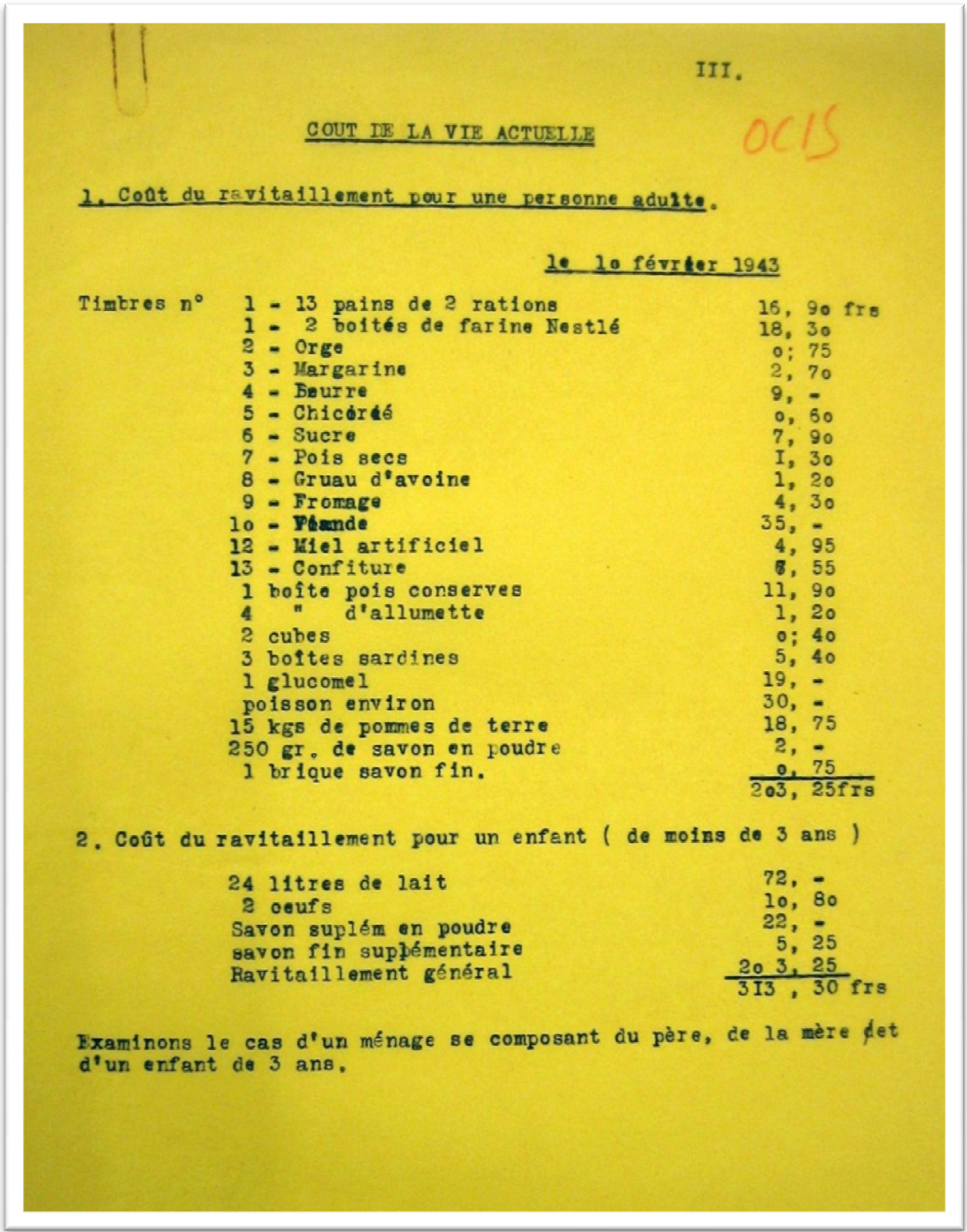




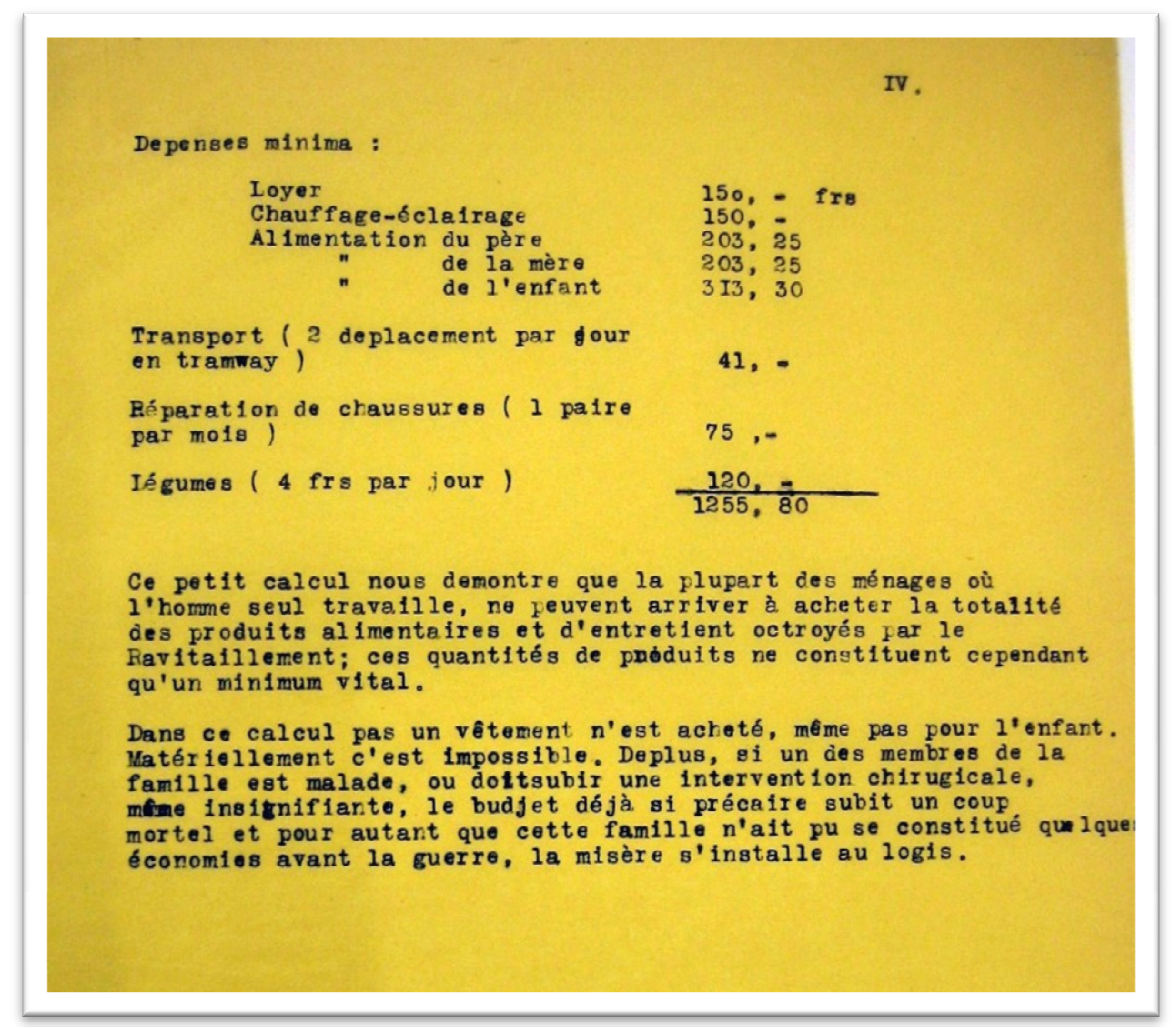

En comparaison avec d'autres revenus du travail en Belgique occupée, on peut s'en tenir aux données suivantes : si les réfugiés pouvaient exercer une activité rémunératrice, ils gagnaient bien moins qu'un mineur (1.300-1.800 francs) et leur revenu était même inférieur au niveau le plus bas des travailleurs obligatoires (juifs et non juifs) occupés par les Allemands (990 francs) ${ }^{127}$. En ce qui concerne les bénéfices du commerce au noir ou d'une activité d'intermédiaire, on ne dispose que de peu de données. Il devait y avoir un large éventail de revenus possibles en la matière. Quand quelqu'un vendait illégalement dans la rue

127 Rapport d'activité de l'Abwehrstelle-Belgique pour décembre 1940, édité dans L. Nestler (Hrsg.), Die faschistische Okkupationspolitik in Belgien..., op. cit., pp. 133-134; A. Godfroid, « À qui profite... », op. cit. (voir note 66), p. 113. 
du chocolat avec un bénéfice de l'ordre de 3,5 francs la tablette, il devait réussir à vendre en moyenne cinq tablettes par jour pour atteindre les 500 francs par mois de revenu minimal d'une aide-cuisinière.

\section{Réfugiés sans revenus}

De quoi vivaient les réfugiés sans travail ? Commençons par la situation matérielle des personnes âgées, des veuves et des invalides ayant fui l'Allemagne. Ceux-ci se trouvaient encore plus mal lotis que d'autres habitants concernés par la persécution des Juifs. Comme ils ne résidaient que depuis peu dans le pays et n’avaient en général pas cotisé aux caisses belges d'assurance sociale, ils ne pouvaient revendiquer aucune indemnité en Belgique. Font exception, et c'est remarquable, quelques rares veuves dont le mari avait été amené en France en mai 1940 par la police belge et avait été tué en cours de route lors de bombardements allemands. Les autorités belges accordaient à ces femmes des pensions belges de veuvage, dont la hauteur ne correspondait certes pas aux frais de leur entretien, mais couvrait au moins le loyer ${ }^{128}$.

Un certain nombre de réfugiés avaient déjà touché chez eux en Allemagne des pensions de vieillesse, d'invalidité ou de veuvage. Leurs pensions furent pour partie versées après leur expulsion d'Allemagne sur des comptes allemands bloqués, auxquels ils n'avaient pas accès ${ }^{129}$. Certains réussirent pourtant à faire transférer leur revenu en Belgique. Ils disposaient ainsi au moins ainsi d'une sécurité de base - jusqu'à ce que les autorités allemandes retirent aux bénéficiaires en fuite leur subsistance. Promulguée en novembre 1941, la onzième ordonnance de la loi sur la citoyenneté du Reich (législation de Nuremberg de 1935) stipulait que les Juifs vivant à l'étranger perdaient la nationalité allemande et que leur fortune revenait au Reich allemand. À côté d'un groupe relativement restreint d'émigrants installés en Belgique avant 1933, cette ordonnance toucha les Juifs qui avaient fui l'Allemagne nazie. D’après notre décompte, plus de 13.000 réfugiés juifs vivaient en Belgique sous l'occupation allemande, dont la moitié étaient déten-

\footnotetext{
${ }^{128}$ AGR, Séquestre-BTG, 653, Dossier Klara R.

129 C'est également valable pour les pensions du secteur privé (AGR, Séquestre-BTG, 3046, Dossier Georg S.).
} 
teurs de la nationalité allemande ${ }^{130}$. Qu'il s'agisse d'invalides de la Première Guerre mondiale, de pensionnés ou de veuves (de guerre), quiconque bénéficiait d'une allocation dut s'en passer dès le début 1942 ou à partir du printemps de la même année. Les pensions qui se trouvaient sur des comptes bloqués en Allemagne échurent également au Reich $^{131}$.

\section{Vol des réserves}

Il en va de même d'autres biens, la plupart du temps bloqués, que les réfugiés allemands avaient abandonnés dans leur pays d'origine, tels des avoirs bancaires, des titres, des assurances-vie, des créances sur des tiers, des biens immobiliers, des collections de timbres et ainsi de suite $^{132}$. Certains Juifs qui avaient quitté légalement le Reich hitlérien avaient, après retenue d'énormes contributions fiscales, entreposé dans des ports allemands d'outre-mer ou versé sur les comptes d'expatriés ce qui restait de leurs propriétés en mobilier et en argent. Les sommes avaient été officiellement débloquées aux fins d'émigration dans les années trente par les bureaux des contributions, avant la fuite vers la Belgique, où la plupart n'obtenaient initialement qu'un droit de séjour transitoire, dans l'attente de l'autorisation d'immigrer sur le continent américain qu'ils espéraient encore à l'époque. Destinés à un nouveau commencement loin de la barbarie nationale-socialiste, ces biens finirent eux aussi par être transférés au fisc allemand ${ }^{133}$.

\footnotetext{
130 I. Meinen - A. Meyer, op. cit., p. 140. Que le nombre beaucoup plus faible de ressortissants allemands qu'on trouve dans le rapport de la Commission Buysse (Les Biens des victimes...,op. cit, p. 149) est estimé beaucoup trop bas, ressort aussi de la comparaison avec différentes sources d'époque, comme par exemple le rapport final du Groupe XII du personnel administratif militaire (voir n. 48), pp. 119-120.

131 AGR, Séquestre-BTG, 654, déclaration de biens d'Eduard G., 26.8.1942 ; déclaration de biens de Louis L., 24.8.1942; ibid., 655, déclaration de biens de Josef et Alma R., 27.8.1942 ; déclaration de biens de Mathilde M., 27.8.1942 ; Kazerne Dossin, AJB, 21D, Service social, Rapports individuels, 175. Voir la contribution fondamentale de Petra Kirchberger, «Die Stellung der Juden in der deutschen Rentenversicherung », dans Beiträge zur nationalsozialistischen Gesundheits- und Sozialpolitik, 5, 1983, pp. 111-132.

132 AGR, Séquestre-BTG, 3043-3046 ; 698, Dossier Julius H.

133 Lettre à l'Anmeldestelle für Judenvermögen, 25.8.1942, AGR, Séquestre-BTG, 3045, Dossier Carl M. ; Aktennotiz BTG, 26.11.1943, ibid., 654, Dossier Nathan A.
} 
Lors de l'identification des biens, les autorités d'Occupation collaboraient avec les agences du Reich. Dès 1940, l'expansion européenne du régime national-socialiste avait entraîné la persécution au-delà des frontières des Juifs échappés d'Allemagne. C'est ainsi que le Devisenschutzkommando, qui avait pénétré en Europe occidentale avec les troupes de la Wehrmacht en tant que branche de la douane allemande, poursuivait délibérément les réfugiés sur qui pesait le soupçon d'avoir exporté leurs possessions d'Allemagne sans autorisation et de ne pas s'être acquittés de la « Reichsfluchtsteuer » (impôt sur la fuite du Reich) et autres taxes spéciales. Suite à ce type d'accusations, les fonds et objets de valeur dont les intéressés disposaient encore en Belgique furent confisqués ; divers réfugiés furent condamnés et internés ${ }^{134}$.

Les autorités allemandes n'en voulaient pas seulement aux possessions demeurées en Allemagne, mais à l'ensemble de la fortune privée des ex-citoyens allemands. Pour pouvoir confisquer de manière générale les possessions situées en Belgique de ces réfugiés, le commandant militaire Alexander von Falkenhausen promulgua en avril 1942 une ordonnance à cet effet ${ }^{135}$. À l'été 1942, la section économique de l'administration militaire, qui fit appel pour identifier les personnes concernées et leurs comptes en banque aux communes et banques belges, ordonna par voie postale à une partie des Juifs allemands dénaturalisés de déclarer l'ensemble de leur fortune privée sur des formulaires spécialement préparés. À cette occasion, l'adresse précédente en Allemagne devait être également précisée, afin de pouvoir prendre contact avec les services locaux ${ }^{136}$. D'autres durent remplir les mêmes formulaires au camp de transit de Malines avant leur déportation. Cela était exigé de tous les Juifs lors de leur arrivée à la caserne Dossin.

Certains émigrants allemands, qui dépendaient de leurs réserves pour vivre, s'élevèrent, lorsqu'ils furent contraints de déclarer leur fortune, contre le procédé du commandant militaire. Indignés, ils firent

\footnotetext{
134 Ceges, AA 585/53/1 ; I. Meinen, « Die Deportation der Juden aus Belgien und das Devisenschutzkommando », dans Besatzung, Kollaboration, Holocaust. Neue Studien zur Verfolgung und Ermordung der europäischen Juden (= Schriftenreihe der Vierteljahrshefte für Zeitgeschichte, vol. 97 - 2008), pp. 45-79.

135 Ordonnance du 1.12.1941, Verordnungsblatt des Militärbefehlshabers in Belgien und Nordfrankreich (VOBIB), p. 872. Voir aussi, pour l'application de l'ordonnance : Les Biens des victimes..., op. cit., pp. 147-150.

${ }^{136}$ La lettre est conservée à Kazerne Dossin, Reliques Hugo Bauman.
} 
valoir que dès leur départ d'Allemagne ils avaient, en application de la réglementation, cédé la majeure partie de leurs avoirs, « si bien que, comme le formulait l'un d'eux en août 1942, ne devrait m'être à nouveau pris le peu que je possède encore, après plus de six ans d'exil, du peu qu'il m'a été permis d'emporter à l'époque ${ }^{137}$. Selon des informations administratives allemandes, la fortune de quelque 5.000 Juifs antérieurement allemands fut enregistrée en Belgique jusque fin 1942. Par la suite, l'administration militaire promulgua des décisions de recouvrement qui, en avril 1943, avaient déjà été appliquées pour 1.200 individus ou familles ${ }^{138}$. Les avoirs bancaires identifiés, bloqués, centralisés et échus au Reich des Juifs allemands dénaturalisés ne furent, si l'on suit les résultats de la recherche, réellement transférés que dans trente cas sur des comptes allemands ${ }^{139}$. Cela pourrait indiquer que l'administration militaire procéda sans trop d'énergie au vol des avoirs bancaires. Dans le contexte qui nous occupe, il est néanmoins d'importance secondaire de savoir si le transfert des biens fut effectivement opéré. La question décisive est plutôt de savoir quelle fortune les réfugiés possédaient, dans quelle mesure ils purent y recourir, comment ils tentèrent de sauver leurs ressources et à quel point ils étaient à même d'assurer leur subsistance sur cette base.

\section{Ressources propres}

À l'examen des dossiers qui nous sont parvenus, on est frappée d'emblée du peu de propriétés immobilières - indice supplémentaire de la situation spécifique dans laquelle les réfugiés se trouvaient encore sous l'occupation allemande. De fait, dans une communauté façonnée avant tout par l'immigration, la proportion de ceux qui possédaient des propriétés immobilières n'était pas considérable. Les réfugiés qui pour la plupart avaient émigré d'Allemagne peu de temps avant la

\footnotetext{
137 Bruno Kantorowicz au Gruppe XII, 27.8.1942, AGR, Séquestre-BTG, 3044, Dossier Bruno K. Six semaines plus tard, Bruno Kantorowicz, qui avait émigré en 1936 de Berlin en Belgique, fut déporté de Malines à Auschwitz à l'âge de 72 ans. Des lettres similaires se trouvent : ibid., 3043, Dossier Elsa C. ; ibid., 3044, Dossier Max K.

138 MBB, rapport d'activités de la Militärverwaltung du 31.12.1942 et du 15.4.1943, Bundesarchiv-Militärarchiv (Freiburg), RW 36/191 (p. D 22); 192 (p. D 25).

139 Les Biens des victimes..., op. cit., p. 150.
} 
Seconde Guerre mondiale ne disposaient qu'exceptionnellement de maisons en Belgique ${ }^{140}$. Ils louaient des appartements ou des chambres; certains d'entre eux partageaient avec des proches une unique pièce. Beaucoup de réfugiés ne possédaient pas non plus (ou très peu) de réserves sous forme d'espèces ou d'avoirs bancaires, comme cela apparaît dans les documents de provenances diverses sur lesquels se fonde la présente recherche. Parmi les Juifs qui avaient fui l'Allemagne nazie, il en était pourtant quelques-uns qui, en 1942 encore, disposaient de suffisamment de moyens propres qu'ils pouvaient théoriquement se tirer d'affaire un certain temps grâce à ceux-ci. Si l'on se fonde sur les déclarations de biens des Juifs antérieurement allemands et autres documents de la Treuhandgesellschaft de Bruxelles à partir de la mi-1942, on trouve au moins trente réfugiés ou couples de réfugiés qui possédaient en Belgique une fortune en espèces ou en compte bancaire enregistrée par les services allemands d'un montant à cinq chiffres ; quelques dépôts à six chiffres sont également répertoriés ${ }^{141}$. Les autres sources contiennent quelques autres cas qui établissent qu'une minorité des réfugiés étaient couverts par leur propre épargne. D’autres réfugiés disposaient de quelques milliers de francs belges - une somme assurément insuffisante pour pouvoir en vivre plus d'un mois, mais avec laquelle d'autres revenus pouvaient être cumulés.

Dès la mi-1941, l'occupant avait soumis l'accès des Juifs à leurs titres et, dans des cas spécifiques à leurs comptes, à l'obligation d'obtenir une autorisation. Dès 1940, la possession de devises était soumise à déclaration. En avril 1942, les comptes furent bloqués; en septembre 1942, ils furent rendus inaccessibles à leurs détenteurs. Ces dispositions touchaient tous les Juifs - pour autant que leurs comptes aient été identifiés comme "comptes juifs", ce qui n'était le cas que pour une part seulement, comme nous le savons ${ }^{142}$. L'administration militaire laissa néanmoins aux Juifs non allemands la possibilité de

\footnotetext{
140 Si l'on s'en tient au fichier des membres de l'AJB, $6 \%$ des Juifs autochtones vivaient dans leur propre maison ou appartement, alors que parmi les réfugiés cette proportion est de $0,1 \%$. Ces chiffres sont basés sur notre évaluation de 7.352 ménages (63\% des fiches conservées), dont un cinquième environ sont des ménages de réfugiés. 141 Les déclarations conservées se trouvent aux AGR, Séquestre-BTG, 653-657, 693, 698, 3043-3046 ; Archives nationales (Paris), AJ 40/230. Nous avons converti en francs belges les montants en devises étrangères selon les taux de change fixes de l'époque. 142 Les Biens des victimes..., op. cit.
} 
prélever régulièrement sur leur compte une certaine somme pour assurer les besoins quotidiens. Les Juifs allemands n'avaient quant à eux plus du tout accès à leurs comptes sans autorisation exceptionnelle de l'occupant, leur fortune ayant déjà échu au Reich allemand. Ils étaient obligés de redemander régulièrement le déblocage de leurs actifs par le biais d'une procédure d'autorisation exceptionnelle. On commença généralement par y accéder positivement, la plupart du temps avec des réserves, mais à partir de fin 1942 les refus se multiplièrent. Tantôt l'arbitraire des fonctionnaires allemands en charge prévalait, tantôt ils appliquaient la règle selon laquelle $80 \%$ de l'argent devait échoir au Reich et que $20 \%$ seulement pouvaient donc être débloqués. Une autre règle voulait que 2.000 francs au moins devaient rester au Reich allemand. De la sorte, cette situation amena des réfugiés à ne plus pouvoir vivre de leurs réserves, alors même qu'ils en avaient suffisamment ${ }^{143}$.

Comment les réfugiés réagirent-ils ? De quelle manière tentèrent-ils de se défendre contre le vol de leurs moyens d'existence ? Si l'on examine les déclarations des ex-citoyens allemands à partir de 1942, les montants relativement élevés en liquide sautent aux yeux. Même parmi ceux qui possédaient un compte en banque, il s'en trouve un bon nombre pour indiquer quelques milliers de francs en liquide, alors que leurs comptes $n$ 'indiquent que des montants minimaux ${ }^{144}$. Manifestement, ils entretenaient l'espoir que des billets soient plus sûrs qu'un actif bancaire. Ce calcul devait s'avérer exact. Il correspondait à la façon de faire des autorités allemandes. L'accès aux comptes fut en général bloqué ; détenir du liquide ne présentait par contre de danger qu'en cas de contrôle policier, d'arrestation ou de perquisition. Une autre stratégie de survie consistait à porter sur soi ses propres réserves sous forme d'un bijou spécifique. Y recouraient des Juifs qui, sous l'occupation allemande encore, envisageaient de se risquer à fuir illégalement à l'étranger, parmi lesquels au moins quelques réfugiés allemands isolés ${ }^{145}$.

143 Voir e.a. AGR, Séquestre-BTG, 3044, Dossier Ida L. ; ibid., 3045, Dossier Max G. ; Dossier Carl M.

144 Voir, par exemple : AGR, Séquestre-BTG, 654, Dossier Flora F.; ibid., 655, Dossier Friedrich B. ; ibid., 655, Dossier Lola B.

145 Ceges, AA 585/54/13. 
On peut se demander pourquoi les persécutés déclaraient leur fortune. Il faut d'abord tenir compte du fait que nous ne pouvons déterminer combien de réfugiés allemands ne déclaraient leurs avoirs qu'incomplètement. D'ailleurs, de l'avis du fonctionnaire responsable de la section économique à l'état-major de l'administration militaire, les déclarations des ex-citoyens allemands qui avaient lieu non en conséquence d'une mise en demeure personnelle écrite, mais dans le cadre de la procédure d'admission au camp de Malines, étaient en partie incomplètes ${ }^{146}$. Par ailleurs, les conséquences que pouvaient entraîner des indications inexactes ont dû à l'époque être difficiles à estimer, d'autant plus que les banques furent, elles aussi, tenues à déclaration. Dès lors que l'on ne dépendait que de soi-même, que l'on ne se livrait à aucun travail régulier et ne percevait aucune allocation, il était à peine croyable que l'on ne possédât rien. Restait dans ce cas comme unique source de revenus le marché noir. C'est pourquoi ceux qui étaient contrôlés, sous l'occupation allemande, par la Police belge des Étrangers devaient indiquer, face à cette autorité, d'où ils tiraient leurs moyens de subsistance et, le cas échéant, présenter du liquide ou des objets de valeur. Dans un cas, un réfugié dut même rendre compte de ses ressources après qu'il eut trouvé une cache pour échapper à la déportation à Auschwitz ${ }^{147}$.

\section{Soutien par des tiers et aide sociale}

La situation particulière des réfugiés échoués dans différents pays était surtout marquée par la séparation forcée des membres d'une même famille. En conséquence, il y avait en Belgique - comme dès avant l'occupation allemande - des réfugiés nécessiteux qui dépendaient de l'aide que des parents leur envoyaient de l'étranger. C'était le

\footnotetext{
146 Pichier à la BTG, 8.12.1942, AGR, Séquestre-BTG, 708. Les cas dans lesquels les Juifs allemands ont rempli deux formulaires d'inscription, l'un à domicile, l'autre à Malines, montrent également que les déclarations de biens au camp de Malines sont incomplètes. Il est possible que la procédure d'enregistrement avilissante au camp ait joué un rôle. Pour des détails à ce sujet, voir A. Meyer, « Boden oder : Das Wissen um Auschwitz », dans Theresienstädter Studien und Dokumente, 2008, pp. 115-147; L. Schram, «Au camp de rassemblement pour Juifs de Malines. Les maîtres de la Aufnahme », dans Les Cahiers de la Mémoire contemporaine, 8, 2008, pp. 13-34.

${ }_{147}$ I. Meinen - A. Meyer, op. cit., pp. 96-98.
} 
cas d'hommes et de femmes tombés dans la pauvreté, qui demandaient de l'argent à des parents qui se trouvaient pour leur part dans d'autres pays d'exil. C'était également le cas de quelques épouses et mères qui, lorsque la guerre éclata, se virent refuser l'autorisation de rejoindre leur mari émigré en Angleterre, qui envoyait régulièrement de l'argent à la famille demeurée en Belgique. C'était enfin le cas pour une série de réfugiés ayant obtenu procuration de leurs maris, fils et frères qui avaient fui ou été expulsés de Belgique en 1940 pour disposer de leur compte en banque en vue de financer leur quotidien ${ }^{148}$. Survivre de la sorte s'avérait difficile, du fait que le recours à tous ces moyens sous la domination allemande n'était possible, suite à diverses ordonnances, qu'avec l'autorisation de l'administration militaire. Les fonctionnaires de la section économique mettaient parfois tant de temps à traiter le dossier que l'octroi n'avait lieu qu'alors que les demandeurs avaient déjà été déportés à Auschwitz. Dans d'autres cas, l'autorisation de disposer de l'argent, qui devait être sollicitée à nouveau toutes les deux ou trois semaines, fut d'abord accordée, mais méthodiquement refusée à partir de 1942 ou 1943149. En outre, des réfugiés individuels réussissaient à recevoir de l'aide de Juifs vivant en Belgique. C'est ainsi qu'un ancien directeur d'usine bien nanti, qui avait émigré d'Allemagne en Belgique dès 1933, payait une rente mensuelle à plusieurs autres réfugiés, jusqu'à ce que l'occupant lui retire en 1942 l'argent de ces rentes. Il fut lui-même déporté ${ }^{50}$.

En ce qui concerne l'action des institutions de bienfaisance auxquelles recouraient les réfugiés, l'aide sociale des communes belges se situe quantitativement de loin à la première place. Il est remarquable que les autorités belges vinssent en aide à des Juifs - étrangers de surcroît - au lieu d'adopter les critères raciaux de l'occupant, lesquels

148 AGR, Police des Étrangers, Dossiers individuels, A 331.036 ; AGR, Séquestre-BTG, 3043, Dossier Leo G.; ibid., 3044, Dossier Irma H.; ibid, Dossier Ernst K. Pour la période avant 1940, voir I. Meinen - A. Meyer, op. cit., pp. 39-40.

149 AGR, Séquestre-BTG, 3043, Dossier Stefanie S. ; ibid,, 3044, Dossier Fritz L. ; ibid., Dossier Luise J. ; ibid., 3045, Dossier Carl. M. ; ibid., 3044, Dossier Lotte L.

150 Ibid., 3045. Il s'agit de Paul Meyer, né en 1881 à Duisburg, qui fut déporté par le XIVe convoi en octobre 1942. David Ferdman, qui n'était pas réfugié, dont les activités considérables de donateur sont référencées dans la littérature spécialisée et qui a coopéré avec l'AJB et le Comité de Défense des Juifs, a également secouru certains réfugiés. Kazerne Dossin, AJB, 21D, Service social, Rapports individuels, 190 ; 133. 
voulaient exclure les Juifs de l'aide publique aux indigents. Certes, des pressions étaient exercées sur les réfugiés aptes au travail pour les pousser à chercher un emploi, mais cela ne change rien au fait que beaucoup de réfugiés juifs pouvaient, sous l'occupation allemande, solliciter de l'argent des caisses d'aide sociale belges. Un certain nombre d'entre eux recevaient en supplément des vivres du Secours d'Hiver, qui relevait également de l'État belge. En outre, les réfugiés dans le besoin se présentaient à des organisations juives d'entraide en Belgique et à des comités locaux de la communauté juive obligatoire (AJB) fondée sur injonction de l'occupant ${ }^{151}$. De plus, il y avait le Hilfswerk für die Juden aus Deutschland, géré par des émigrants allemands, qui offrait un "vestiaire" et un bureau de placement et qui, comme les autres organisations juives de secours, fut incorporé en 1942 à l'AJB. Manifestement, certains bénéficiaient d'assistance de ce côté. On ne peut préciser le nombre de réfugiés qui parvinrent à subsister avec l'aide des institutions juives ${ }^{152}$.

Comme on pouvait à peine vivre des allocations de secours, d'autres rentrées devaient s'y ajouter, que ce soit des aides privées, des ressources propres, des emplois occasionnels, du commerce au noir ou la sous-location d'une chambre. Il est évident que les personnes qui ne disposaient que d'une allocation sociale (ou ne recevaient même pas celle-ci) devaient puiser dans leurs propres réserves.

\section{Puiser dans ses propres réserves}

Les exemples suivants illustrent la manière dont les réfugiés juifs vendaient progressivement tous leurs biens : «Jusqu'au 10 mai 1940,

151 Ceux-ci étaient principalement la Centraal Beheer van Joodse Weldadigheid en Maatschappelijk Hulpbetoon et l'EZRA à Anvers, ainsi que l'OCIS (l'CEuvre centrale israélite de Secours) à Bruxelles.

152 Dans les dossiers individuels de la Police belge des Étrangers et des autorités d'occupation allemandes, les organisations juives d'assistance sont rarement citées, tandis que l'assistance publique communale est souvent mentionnée. Cependant, il n'est pas exclu que cela soit également lié à la nature des sources. Les archives de l'AJB ne permettent pas de quantification. Dans les documents statistiques conservés de l'AJB, les réfugiés ne sont pas présentés séparément, les dossiers individuels ne sont conservés que pour une faible part. Sur les œuvres caritatives juives en général, voir C. Massange, « La politique sociale... » (voir note 8 ). 
j’ai été représentant en cuirs, puis je suis tombé au chômage. De temps à autre, j'effectuais des petits travaux pour gagner quelque chose. J'ai vendu tous mes meubles pour assurer mon quotidien. » (Mai 1941, Bruxelles, interrogatoire par le Devisenschutzkommando d'un commerçant en cuirs ayant fui Francfort en 1939) ${ }^{153}$.

« L’intéressée n’émarge pas à la Commission de l'Assistance publique et vit de la vente de ses meubles, faïences et fourrures. Ses économies actuelles se montent à 3.400 frs. » (Mars 1942, BruxellesSchaerbeek, rapport de la police belge sur une femme ayant fui Berlin en 1939) ${ }^{154}$.

« Mme B. reçoit Frs. 161.- par semaine du Secours Civil. Elle a vendu tout ce qu'elle possédait, son linge, etc. Elle vend également les timbres de ravitaillement dont elle peut se passer pour pouvoir acheter le plus strict nécessaire. Elle habite une petite mansarde, qu'elle paye Frs. 100, -. Depuis 2 mois, elle n'a pas pu payer son gaz. [...] La femme est dans une situation lamentable, n'ayant pas un sou pour payer le loyer. » (Mai 1943, Bruxelles-Anderlecht, rapport du Service social de l'AJB sur une mère et ses deux fils mineurs qui ont fui Vienne en $1938)^{155}$.

Les réfugiés nécessiteux mettaient d'abord en gage des objets de valeur, tels que des montres ou des bijoux, puis des vêtements, des chaussures, du linge et de l'ameublement. Il ne restait à ceux qui avaient échangé tout ce qu'ils avaient contre de l'argent que la possibilité de vendre chaque mois une partie de leurs timbres de ravitaillement pour du beurre, du sucre ou de la viande. Cette façon désespérée de gagner de l'argent menait à l'épuisement, d'autant plus que le taux de rationnement de la population civile dans le pays pillé par les Allemands se situait déjà bien en dessous de ce qu'il était dans le Reich allemand ou aux Pays-Bas.

${ }^{153}$ Interrogatoire de Walter G., DSK Brüssel, 22.5.1941, Ceges, AA 585/52/8.

154 Le bourgmestre de Bruxelles-Schaerbeek au Ministère de la Justice, 24.3.1942, AGR, Police des Étrangers, Dossiers individuels, A 391.455. Estera Traubman, dont il est ici question, fut déportée à Auschwitz sept mois plus tard.

155 Rapport du service social de l'AJB de Bruxelles, 3.5.1943, Kazerne Dossin, AJB, 21D, Service social, Rapports individuels, 169. La lettre concerne l'Autrichienne Juliana Blau Osman, dont le mari a été interné en France. En 1944, elle fut déportée par le convoi XXV. Leurs enfants ont survécu à l'Occupation. 
Le plus répandu était sans doute la vente des meubles. Les indications disponibles quant au logement et à l'ameublement montrent qu'un nombre respectable de réfugiés avait vendu tous leurs objets d'usage courant dès la mi-1942 ou 1943, pour autant qu'ils n'aient pas été d'emblée dépourvus de moyens. Ces réfugiés indiquaient comme logement, lors de leur déclaration de fortune en août 1942 (ou plus tard), un appartement meublé ou une chambre meublée et firent remarquer qu'ils ne possédaient aucun meuble. Dans les formulaires d'enregistrement ainsi que dans d'autres documents de l'occupant, des autorités belges et de la communauté juive obligatoire précités, on trouve d'ailleurs à maintes reprises l'indication explicite que les meubles ont été vendus pour pouvoir faire face aux besoins du quotidien.

Après le début de la déportation des Juifs de Belgique à Auschwitz - le premier convoi partit le 4 août 1942 -, les autorités allemandes commencèrent aussi à prêter attention au fait que les Juifs vendaient leurs meubles. Le chargé des affaires juives de la Sipo-SD de Bruxelles informa même Berlin que les salles de vente aux enchères en Belgique étaient « encombrées de biens appartenant aux Juifs», et, en septembre 1942, le commandant militaire promulgua une dernière ordonnance antijuive afin d'interdire la vente de mobilier sans autorisation allemande ${ }^{156}$. Comme on le sait, le régime nazi avait décidé de faire main basse sur ces actifs et de les envoyer en Allemagne dans le cadre de la « Möbelaktion ». Depuis l'ordonnance d'avril 1942 qui saisit leurs biens au profit du Reich allemand, les ex-citoyens allemands parmi les réfugiés vivaient déjà sous la menace que leurs meubles puissent être à tout moment emportés. Certains rédigèrent des requêtes bouleversantes dans lesquelles ils sollicitaient qu'on ne leur enlève pas leur unique lit. Effectivement, l'enlèvement de l'ameublement eut lieu après le début de la déportation et il n'affecta pas seulement les réfugiés ex-allemands, mais de manière générale les ménages dont les habitants avaient été déportés par les adjoints d'Eichmann.

En convertissant leurs biens en argent, les Juifs prévenaient leur dépossession par les Allemands. La Sipo-SD considérait, sans doute à

156 Meldungen aus Belgien und Nordfrankreich vom 31.8.1942, Bundesarchiv (Berlin), R 58/6399. Voir aussi à ce propos le rapport final du Groupe XII du Militärverwaltungsstab (voir note 49), p. 112. 
raison, qu'un certain nombre de ces ventes préludaient à une fuite. Dans d'autres cas, la cause doit en avoir été la simple nécessité. À ce qu'il semble, vendre ses meubles - une pratique de longue date des réfugiés - devint à partir de l'été 1942 également l'une des stratégies de survie des Juifs établis depuis plus longtemps. Car la paupérisation d'une part croissante de la population juive totale s'étendait : du fait de la pénurie causée par l'occupant et des mesures antijuives de l'année 1942 - en particulier l'exclusion du circuit économique -, de plus en plus de Juifs avaient perdu leur travail.

Chaque mois que perdurait la domination nazie, les ressources des persécutés allaient déclinant. Depuis le début de la « solution finale », leur situation économique empirait pour plusieurs raisons. Bon nombre de Juifs perdirent leur travail parce que leur employeur fut déporté. Des réfugiés âgés pauvres et sans pension qui avaient été soutenus par leurs enfants se retrouvèrent sans moyens d'existence après la déportation de ceux-ci. Et surtout, un nombre relativement élevé de Juifs se décidaient en Belgique à quitter leur domicile déclaré et à vivre dans la clandestinité pour éviter d'être arrêtés. Cette démarche occasionna de nouveaux problèmes de survie matérielle. Une activité professionnelle réglée était difficilement compatible avec la vie clandestine. Celui qui ne vivait pas à son adresse légale ne pouvait pas non plus toucher d'allocation sociale officielle. L'exemple d'une ex-employée ayant fui l'Allemagne, qui reçut l'argent du bureau de l'aide sociale communale jusqu'à ce qu'elle "plonge dans la clandestinité" en décembre 1942, montre que des Juifs pauvres prenaient ce risque. Les mois suivants, elle assura son logement en vendant tout ce qu'elle avait et en crochetant des gants. C'est alors qu'elle sollicita l'assistance de la Communauté juive obligatoire ${ }^{157}$. En effet, le service social de l'AJB ne faisait pas dépendre son aide d'un domicile légal et collabora avec la résistance juive - le Comité de Défense des Juifs (CDJ), qui organisa surtout la cache des enfants, mais soutint également des Juifs adultes dans la clandestinité. Toujours est-il qu'une fraction seulement des adultes passés dans la clandestinité ont pu profiter de ces aides.

157 Kazerne Dossin, AJB, 21D, Service social, Rapports individuels, 166. Pour des informations complémentaires, voir C. Massange, « La politique sociale... » (voir note 8). 


\section{Conclusion}

À l'époque de l'occupation allemande durant la Seconde Guerre mondiale, près d'un Juif sur quatre vivant en Belgique était un réfugié, qui avait échappé la plupart du temps dans les années 1938-1939 à la persécution et à la violence antijuives en Allemagne nazie. Lorsque débutèrent les recherches en archives pour la présente étude, on ne s'attendait pas à rassembler beaucoup d'informations sur le travail et la subsistance de cette masse anonyme de réfugiés juifs. Parmi les résultats étonnants, il faut compter en premier lieu qu'un grand nombre d'hommes et de femmes réussissaient à trouver du travail. L'éventail est considérable - toutes les activités des réfugiés sont du reste sans doute loin d'être documentées, notre présentation ne prétendant nullement à l'exhaustivité. Il allait, pour ne faire état que de trois priorités, du travail de tailleur et de la couture à domicile au commerce au noir en passant par l'occupation d'aide-ménagère. Dans la lutte des réfugiés pour la survie entre 1940 et 1944, le fait que beaucoup devaient se procurer d'autres revenus - à la place ou en sus d'un travail rémunéré - est au moins aussi important. Indépendamment des économies qu'ils n'avaient que dans une mesure très limitée, nous trouvons dans les documents comme sources typiques de revenus l'aide d'un tiers et la vente de leurs effets personnels. Pour vivre, les réfugiés dépendaient en premier lieu de leurs proches et de l'aide sociale belge. En vendant leurs avoirs propres, ils risquaient l'épuisement physique, puisqu'après avoir perdu leur montre, leurs vêtements et leurs meubles, ils étaient finalement contraints de vendre une partie de leurs timbres de ravitaillement pour se faire un peu d'argent.

La situation des réfugiés se distinguait fondamentalement de celle du reste de la population juive. Cela apparut dès mai 1940. Lorsque les troupes allemandes envahirent le pays, les conditions d'existence des réfugiés étaient déjà des plus précaires. Leur détresse résultait aussi bien de la persécution subie dans le Reich allemand que de l'interdiction de travail à laquelle ils étaient soumis en Belgique comme dans d'autres pays refuges. Sous l'occupation allemande, leur vie quotidienne était de surcroît soumise à des restrictions spécifiques, bien que l'interdiction de travailler eût à présent fait place à l'impératif de travailler. En même temps, la mobilité contrainte, qui 
entravait l'activité professionnelle, se poursuivit. En fuite depuis des années, les Juifs ayant quitté l'Allemagne furent expulsés d'Anvers par le commandant militaire allemand, alors que la Police belge des Étrangers leur rappelait régulièrement qu'ils avaient à quitter le pays dès que les circonstances le permettraient. On n’oubliera pas que, à la mimai 1940, les autorités belges expulsaient encore vers la France quelques milliers d'hommes réfugiés, dont les femmes et les enfants devaient donc se débrouiller seuls. C'est au printemps 1942, lorsque l'administration militaire exclut les Juifs de l'économie et liquida leurs entreprises, qu'il apparaît à quel point la participation des réfugiés à la vie économique en Belgique occupée était marginale. D'après ce que nous savons, moins de $3 \%$ des firmes liquidées se trouvaient entre les mains de réfugiés. Ces réfugiés, qui appartenaient dans leur écrasante majorité au groupe très restreint des Juifs émigrés précocement et dans des circonstances plus ou moins régulières d'Allemagne, vivaient en Belgique légalement depuis des années. On ne comptait par ailleurs que peu de femmes parmi les patrons d'entreprises.

Si la liquidation forcée des entreprises toucha relativement moins de réfugiés que de Juifs locaux, d'autres mesures d"aryanisation" par lesquelles l'occupant dépossédait la population juive visaient d'autant plus vigoureusement les réfugiés. C'était les réfugiés à qui les autorités nationales-socialistes avaient dérobé méthodiquement dès 1940 leur argent et leurs biens au prétexte qu'ils avaient été exportés d'Allemagne sans autorisation. C'était les ressortissants allemands, le plus souvent des réfugiés juifs, qui suite à leur déchéance de nationalité ordonnée en 1941 commencèrent par perdre leurs pensions de vieillesse, de veuvage et d'ancien combattant et l'ensemble de leur fortune restée en Allemagne, avant que ce qu'ils pouvaient encore posséder en Belgique n'échoie également à l'État allemand. Ceux qui disposaient d'une épargne sur des comptes bancaires belges enregistrés ne pouvaient plus qu'exceptionnellement y prélever des montants partiels dans le cadre d'une procédure d'autorisation complexe, pour autant que les bureaucrates nationaux-socialistes ne refusaient pas catégoriquement d'y donner suite. Nombre de réfugiés se protégeaient contre cette forme de dépossession en gardant leur épargne en espèces. Les réfugiés étaient particulièrement touchés par la restriction de l'accès à l'argent en provenance de l'étranger ou appartenant à des personnes 
résidant à l'étranger. Car, comme avant mai 1940 déjà, beaucoup de réfugiés avaient besoin des versements d'appoint de parents qui, ayant fui l'Allemagne nationale-socialiste, s'étaient retrouvés dans d'autres pays. La solidarité entre parents vivant en Belgique contribuait également à assurer l'existence. Des réfugiés âgés qui devaient se débrouiller sans pension dépendaient quelquefois de leurs enfants. Cela correspondait à la politique de la Police belge des Étrangers, qui œuvra sciemment à partir de 1941 à restreindre la possibilité pour des réfugiés juifs de toucher des allocations officielles. Elle mit une part des réfugiés chômeurs sous pression, afin qu'ils trouvent l'une ou l'autre occupation pour gagner de quoi vivre et maintenir leurs parents hors d'état de travailler. D'autres réfugiés furent contraints de renseigner à la Police des Étrangers, qui cherchait en même temps à contrer le marché noir, leurs sources de revenus, ce qui ne facilita pas la situation, d'autant plus que des contrôles à cet effet eurent lieu, dans des cas exceptionnels, jusqu'à et y compris la période de la déportation.

Il y avait pour ces réfugiés sous le régime d'occupation des formes typiques de travail. Ceux qui pouvaient trouver un emploi avaient d'ordinaire à accepter des conditions incertaines telles que travail à domicile pour des tiers, petits travaux et coups de main, emplois précaires, activités illégales ou salaires comparativement bas. Il est également frappant qu'un réfugié ou un ménage de réfugiés devait souvent pour s'en tirer combiner diverses espèces de revenus qui se complétaient ou s'alternaient (aide privée ou officielle, vente de leurs meubles, travaux légaux, commerce au noir, etc.). Certaines de ces caractéristiques d'une existence matérielle incertaine ne sont pas spécifiques aux réfugiés juifs en Belgique occupée, mais sont aussi connues pour d'autres époques. Par exemple, le travail à domicile pour des tiers était depuis longtemps le mode d'insertion habituel dans la vie professionnelle des Juifs nouvellement immigrés en Belgique en provenance d'Europe de l'Est. Un autre exemple est fourni par le travail illégal, pour lequel il existe d'innombrables parallèles dans l'histoire de l'exil et de la migration. Que les réfugiés dépendent des activités illégales pour gagner leur vie est, de nos jours encore, un phénomène d'ampleur mondiale. Dans la Belgique des années trente déjà, avant l'occupation par l'armée hitlérienne, un certain nombre de réfugiés juifs d'Allemagne qui ne pouvait obtenir ni permis de travail ni licence tra- 
vaillaient également en sous-main. Tout comme sous l'occupation allemande, les travailleurs au noir étaient alors déjà menacés de dénonciation. Un troisième exemple s'avère également des plus instructifs, à savoir la continuité du travail spécifique des réfugiées, également établie pour des temps plus reculés : des femmes juives en fuite gagnaient de l'argent pour elles-mêmes et leurs familles, avant 1940 comme après, en travaillant, légalement ou non, comme aide-ménagères. Durant l'Occupation, la couture à domicile était sans doute encore plus répandue. Parmi les autres activités ressort le commerce ambulant, qui - et c'est remarquable - n'était pas exercé uniquement par des hommes, mais également par des femmes, qu'elles soient célibataires, que leur mari ait été séparé d'elles par l'exil ou la persécution, ou qu'elles vivent avec lui.

Les parallèles cités ne peuvent masquer le fait que le travail des réfugiés juifs en Belgique occupée était placé sous des augures particuliers qui restreignent la possibilité d'opérer une comparaison avec d'autres époques et d'autres mouvements de fuite. Au nombre des particularités de l'occupation de l'Europe occidentale durant la Seconde Guerre mondiale, on relève le fait que les Juifs chassés d'Allemagne par des atteintes à leur intégrité physique et les dispositions légales antijuives furent rattrapés dans leur exil provisoire par leurs persécuteurs, qui avaient désormais ici aussi le dernier mot. Nombre de réfugiés se virent contraints d'entrer en contact avec les fonctionnaires nationaux-socialistes et les soldats de la Wehrmacht en tant que blanchisseurs, marchands ambulants ou démarcheurs pour trouver des clients solvables et récolter de l'argent. À partir de la mi-1942, lorsque les premiers trains de la « solution finale » quittèrent la Belgique, les réfugiés, tout comme les autres Juifs, travaillèrent sous la menace constante de l'arrestation et de la déportation. Ce n'était pas seulement le cas de ceux qui devaient subvenir à leurs besoins par des occupations illégales : ceux qui avaient après l'exclusion de la plupart des Juifs de la vie active encore une activité légale - par exemple dans des usines d'importance militaire, à l'AJB ou comme médecins - travaillaient aussi dans une incertitude permanente. Parmi eux se trouvaient éga- 
lement quelques réfugiés qui, en dépit d'une activité de cet ordre, furent déportés de Malines à Auschwitz ${ }^{158}$.

Plus de la moitié des réfugiés juifs ont survécu à la domination nazie en Belgique. Néanmoins la proportion de réfugiés parmi les victimes de la Shoah est relativement haute en comparaison avec le reste de la population juive, comme nous l'avons montré ailleurs ${ }^{159}$. Quelles en sont les raisons? On peut exclure la supposition que les réfugiés aient moins cherché que le reste de la population juive à se soustraire au sort que leur réservaient les autorités allemandes. Le fait qu'un nombre bien au-dessus de la moyenne de réfugiés s'échappèrent des convois de Malines à Auschwitz va déjà à l'encontre de cette idée. Le danger particulier couru par les hommes, les femmes et les familles échappés du Reich allemand peut être dû en partie au zèle persécuteur que leurs ex-compatriotes allemands déployaient à leur encontre. En tant qu'étrangers qui n'avaient pour la plupart immigré qu'en 19381939 et n'étaient pas intégrés professionnellement, ils avaient sans aucun doute par rapport aux Juifs autochtones moins de contacts sociaux avec d'autres habitants du pays, dont ils dépendaient assurément s'ils voulaient quitter leur domicile officiel et plonger dans la clandestinité. Les exemples de ces femmes seules ou de ces couples originaires d'Allemagne qui abandonnèrent leur domicile officiel bien qu'ils perdaient ainsi leur unique source de subsistance montrent à quel point la volonté de se cacher était puissante. Enfin, il est évident que la contrainte financière rendait les réfugiés particulièrement vulnérables. Bien sûr, pour les autres Juifs de Belgique également, c'en sera généralement fini au printemps 1942 des occupations professionnelles et revenus réguliers. Mais comme ceux-là avaient été actifs les années précédentes et n'avaient pas depuis 1938 fait l'objet d'une spoliation méthodique, ils doivent avoir disposé de réserves plus importantes que les réfugiés. Reste encore à étudier plus précisément le rapport général entre la situation matérielle des Juifs et leurs chances de survie, mais tout converge vers l'idée que l'extrême pauvreté dans laquelle vivaient

\footnotetext{
158 Kazerne Dossin, Reliques Hugo Baumann; Reliques Itta Brand; Reliques Mejer Nussbaum; Reliques Gertrude Neumann; AGR, Séquestre-BTG, 3044, Dossier Otto H. Voir ci-dessus également les informations sur Alexander Mayer, Alfred Galewski (note 82), Lotti Fingerhut et Otto Wolf (note 86).

159 I. Meinen - A. Meyer, op. cit., pp. 143-151.
} 
beaucoup de réfugiés d'Allemagne leur rendit difficile de se cacher et d'échapper à l'arrestation. 